Portland State University

PDXScholar

$12-2-1991$

\title{
The Concept of Self-disclosure in Initial Interaction Between Strangers in Japan
}

Hizuru Sugita

Portland State University

Follow this and additional works at: https://pdxscholar.library.pdx.edu/open_access_etds

Part of the Speech and Rhetorical Studies Commons

Let us know how access to this document benefits you.

\section{Recommended Citation}

Sugita, Hizuru, "The Concept of Self-disclosure in Initial Interaction Between Strangers in Japan" (1991). Dissertations and Theses. Paper 4536.

https://doi.org/10.15760/etd.6420

This Thesis is brought to you for free and open access. It has been accepted for inclusion in Dissertations and Theses by an authorized administrator of PDXScholar. Please contact us if we can make this document more accessible: pdxscholar@pdx.edu. 
AN ABSTRACT OF THE THESIS OF Hizuru Sugita for the Master of Arts in Speech Communication presented December 2, 1991 .

Title: The Concept of Self-disclosure in Initial Interaction between Strangers in Japan.

APPROVED BY THE MEMBERS OF THE THESIS COMMITTEE:

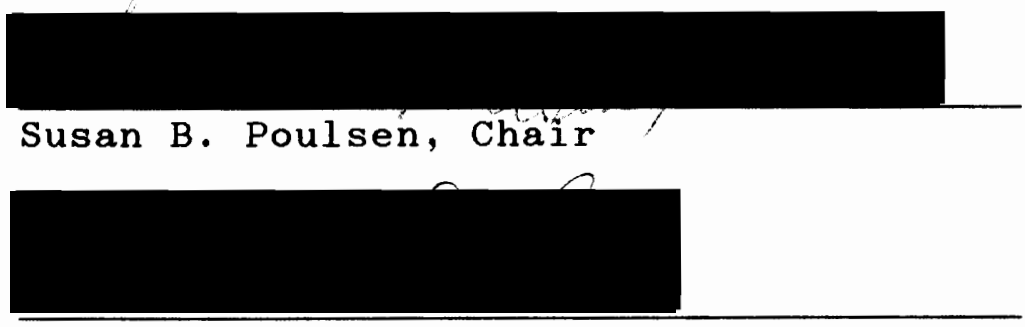

David Ritchie
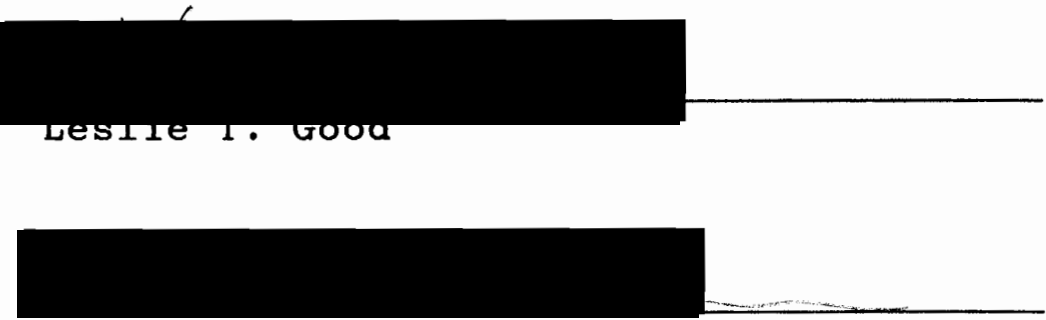

Suwako Watanabe

The study of self-disclosure has been developed and elaborated mainly in the United states, and only a few studies have directly examined self-disclosure in the Japanese cultural context. This study was designed to extend the study of self-disclosure to Japanese culture, and 
using the concept of ingroup and outgroup relationships, examine the relationship between the level of selfdisclosure and perceived social attraction in initial interaction between Japanese strangers. Based on the literature on self-disclosure and features of Japanese culture and communication, two hypotheses were constructed:

H1: For the ingroup members, the high discloser will be perceived to be more socially attractive than the low discloser.

H2: For the outgroup members, the low discloser will be perceived to be more socially attractive than the high discloser.

As respondents, a total of 328 Japanese college graduate and undergraduate students living in the Kansai area in Japan participated in the research. The data collection instrument consisted of McCroskey and McCain's (1974) social attraction scale and a culture-specific scale of social attraction constructed by the researcher. A twoway analysis of variance (ANOVA) and $\underline{t}$ tests were used to test the two hypotheses and interaction between the two variables. In addition, to test gender effects, the data were analyzed by using three, three-way ANOVAs.

The results of the data analyses revealed that in initial interaction between Japanese strangers, the level of self-disclosure was a main factor in determining the stranger's perceived social attraction. Low self-disclosure led to positive evaluation of perceived social attraction, and high self-disclosure led to negative evaluation of 
perceived social attraction. The results also suggested that the stranger's group identification mediated the relationship between the stranger's level of self-disclosure and perceived social attraction. Ingroup membership produced greater perceived social attraction than did outgroup membership. Thus, the highest perceived social attraction was produced by the low disclosing stranger identified as being an ingroup member. Further, Japanese subjects distinguished ingroup and outgroup membership for low self-disclosure, but not for high self-disclosure. No significant effects due to gender were found in this study. 


\title{
THE CONCEPT OF SELF-DISCLOSURE
}

\section{IN INITIAL INTERACTION BETWEEN STRANGERS}

\section{IN JAPAN}

by

HIZURU SUGITA

A thesis submitted in partial fulfillment of the requirements for the degree of

\author{
MASTER OF ARTS \\ in \\ SPEECH COMMUNICATION
}

\author{
Portland States University \\ 1992
}


TO THE OFFICE OF GRADUATE STUDIES:

The members of the Committee approve the thesis of Hizuru Sugita presented December 2, 1991.

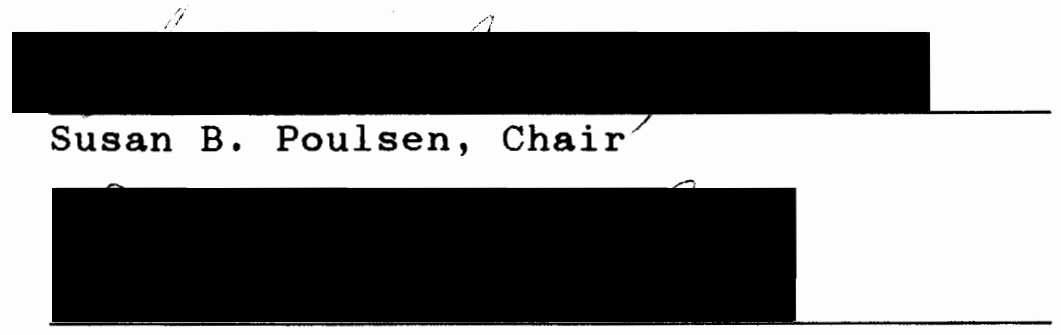

David Ritchie

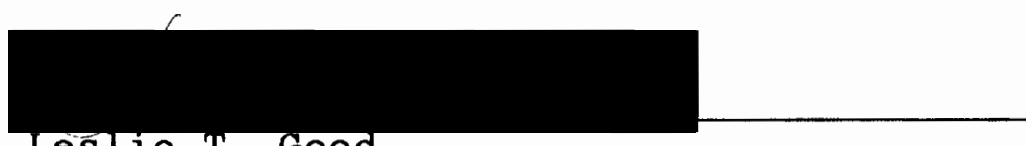

Le'sile T. Good
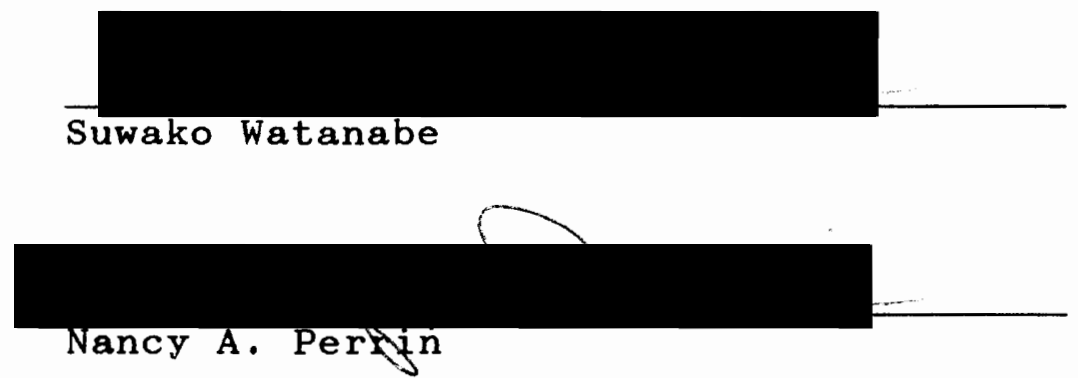

APPROVED :

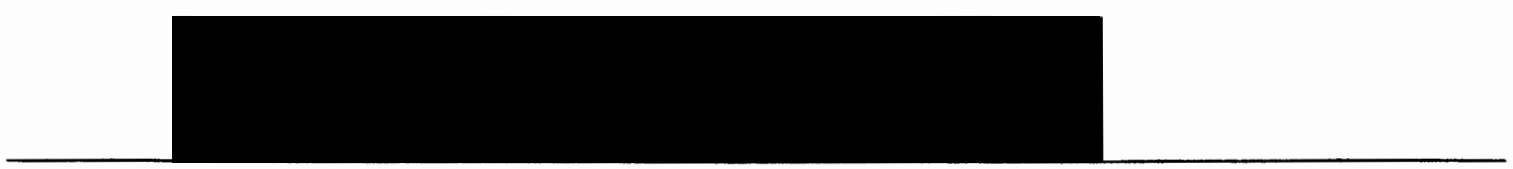

Theodore G. Grove, Chair, Department of Speech Communication

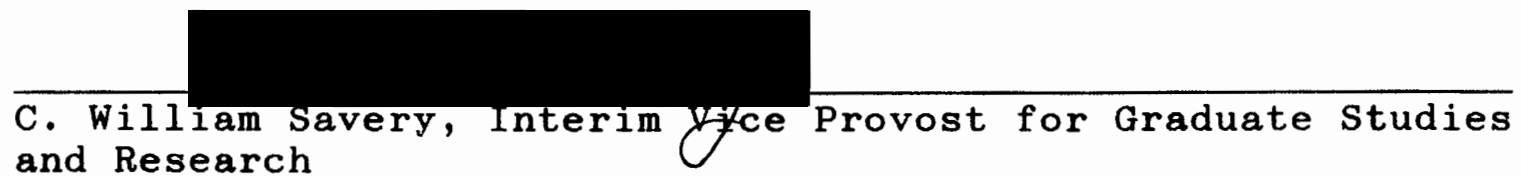


To

my mother in Japan

and

my father in Heaven 


\section{ACKNOWLEDGEMENTS}

I would like to thank Dr. Poulsen, my thesis advisor, Dr. Ritchie, Dr. Good, Dr. Perrin, Dr. Watanabe, Prof. Takahara, Miss Tanioka, and Mr. Yamamoto. They taught me how to write a thesis and helped me complete this Master Thesis. 
TABLE OF CONTENTS

PAGE

ACKNOWLEDGEMENTS ........................

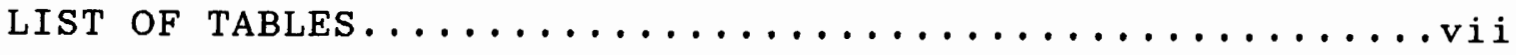

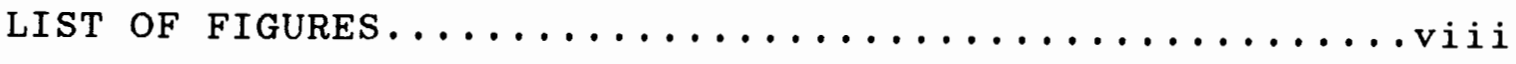

CHAPTER

I INTRODUCTION $\ldots \ldots \ldots \ldots \ldots \ldots \ldots \ldots \ldots \ldots \ldots$

Justification of the study............

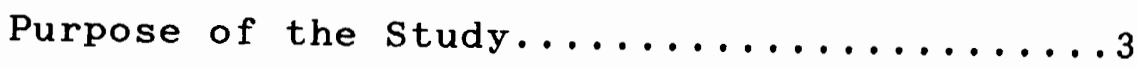

Definition of Concepts..............

Self-disclosure

Social Attraction

Ingroup and Outgroup Relationships

Initial Interaction between Strangers

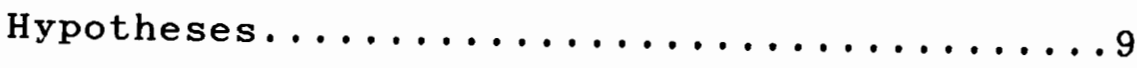

Overview of the Thesis.................

II REVIEW OF THE LiteratuRE................ 11

Self-disclosure and Communication........11

Self-disclosure

Berger and Calabrese's Uncertainty Reduction Theory

Altman and Taylor's Social Penetration Theory

Culture and Communication in Japan.......18

Verbal Communication in $\mathrm{High-context}$ Culture

Interpersonal Relationships in Collectivistic Culture

Self-disclosure in Japanese Culture 
Communication between Strangers in Japanese

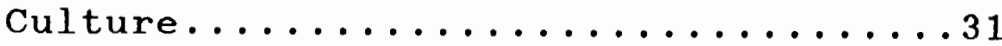

Verbal Communication between strangers Interpersonal Relationships between Strangers

- Self-disclosure between strangers

Assumptions about Initial Interaction between

Japanese strangers...................

III METHODS .......................... 40

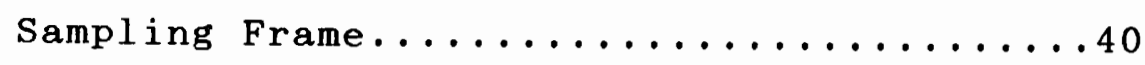

Sample......................... 42

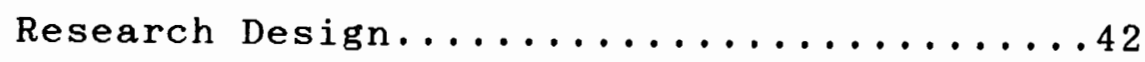

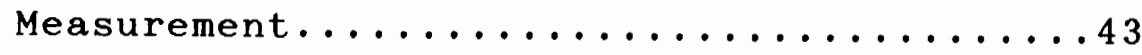

Questionnaire

Scenarios

Scales

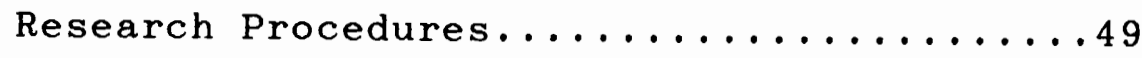

Translation Procedure

Pilot Study

Data Collection Procedure

IV $\quad$ RESULTS.......................... 53

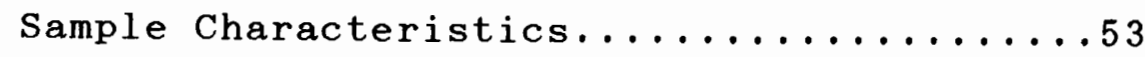

Reliability of Measurement............54

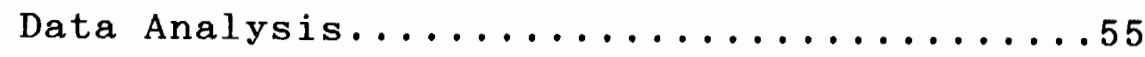

Hypothesis 1

Hypothesis 2

Interaction

Gender

V DISCUSSION AND CONCLUSION.............60

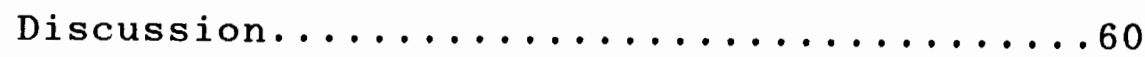

Hypotheses

Interaction

Gender 
Summary of Findings................ 74

Study Limitations and strengths........75

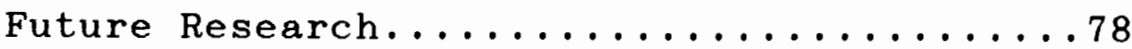

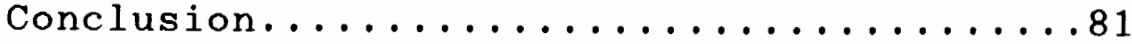

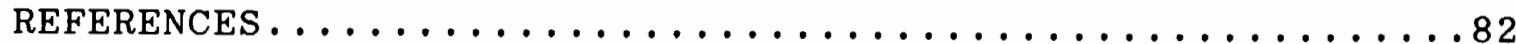
APPENDICES

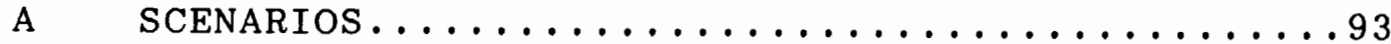

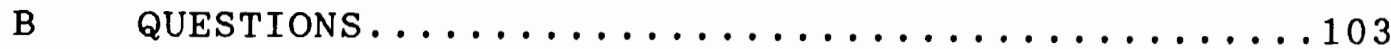

C LETTER TO INSTRUCTORS IN JAPAN............ 105

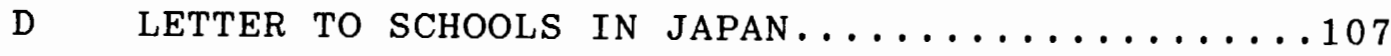

E PERMISSION FROM SCHOOLS IN JAPAN............. 109

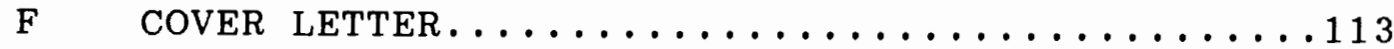

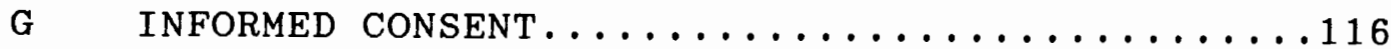

H BIOGRAPHICAL SHEET ...................... 


\section{LIST OF TABLES}

TABLE

PAGE

I Results of the Two-way Analysis of Variance....57 


\section{LIST OF FIGURES}

FIGURE

PAGE

1 Relationship among the Three Variables........42

$2 \quad 2 \times 2$ Factorial Design.................. 43

3 Eight Disclosers in the Eight Scenarios.......45

4 Mean Scores of Perceived Social Attraction for

Four Conditions of the Discloser and the

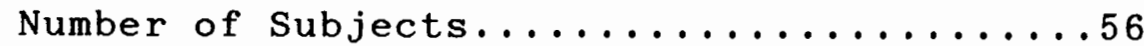

5 Mean Scores of Perceived Social Attraction by the

Discloser's Level of Self-disclosure and

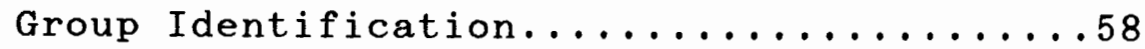


CHAPTER I

\section{INTRODUCTION}

\section{JUSTIFICATION OF THE STUDY}

The study of self-disclosure initiated by Jourard in psychology has developed into a central concept in the field of communication in the United States. Self-disclosure is viewed as an important communication act, and numerous studies have examined the relationship between selfdisclosure and other communication concepts such as reciprocity, liking, and trust (e.g., Berg \& Archer, 1983; Bochner, 1982; Derlega \& Chaikin, 1977; Hosman \& Tardy, 1980 ; Norton, 1982; Wheeless \& Grotz, 1977). Further, selfdisclosure is considered to be a central concept of such communication theories as uncertainty reduction theory and social penetration theory. In initial interaction between strangers, self-disclosure conveys the information necessary to increase the ability to communicate effectively (Berger \& Calabrese, 1975). As relationships develop, exchanged selfdisclosure between interactants increases in variety of topics and intimacy (Altman \& Taylor, 1973).

These studies and theories, which have been developed and elaborated primarily based on data collected in the 
United States, inform the concept of self-disclosure in interpersonal communication in U.S. culture. As Barnlund (1989) contends :

Very little has done to explore the relation between culture and disclosure. The concept itself is a Western one, reflective of selfcentered cosmologies, and measurement of it, unsurprisingly, has been carried out largely in the United States and Great Britain (p. 108).

In other words, the concept of self-disclosure has been generated from an American (Western) viewpoint, not from the viewpoint of members of Japanese culture and thus, the concept of self-disclosure developed in the United States may not necessarily explain communication in Japanese culture.

This study was designed to extend the research on selfdisclosure to the Japanese cultural context. Some researchers have extended the uncertainty reduction and social penetration theories developed in the United States to the Japanese cultural context (e.g., Gudykunst \& Nishida, 1986; Gudykunst, Nishida, \& Chua, 1987; Gudykunst, Yoon, \& Nishida, 1987). However, the findings on self-disclosure among Japanese are even more limited as only a few studies have directly examined self-disclosure in the context of Japanese culture (Barnlund, 1975, 1989; Nakanishi, 1986). Using the concept of ingroup and outgroup relationships in Japanese communication, this study examined the relationship between the level of verbal self-disclosure and perceived 
social attraction in initial interaction between strangers in Japanese culture.

\section{PURPOSE OF THE STUDY}

The purpose of this study was to extend the research on self-disclosure to Japanese culture, and examine selfdisclosure as a communication act in initial interaction between Japanese strangers based on and in comparison with the concept as developed in the United States. This study holds a perspective that cultural variability influences social norms of interpersonal communication. Focusing on three important communicative differences between Japanese and Americans, the study examined self-disclosure in the Japanese cultural context.

First, compared with Americans, Japanese negatively evaluate talkativeness or verbosity. They perceive quietness or silence to be valuable in communication (Kang \& Pearce, 1983; Kindaichi, 1975; Klopf \& Cambra, 1979; Yoshikawa, 1978). Second, Japanese hesitate to express personal feelings and opinions to others (Araki, 1973; Barnlund, 1975, 1989; Iritani, 1971; Kindaichi, 1975; Mizutani, 1979; Okabe, 1983). Third, compared with Americans, Japanese are more group-oriented and use distinctive communication styles in interaction with individuals considered ingroup and outgroup members (Hall, 1976; Nakane, 1974; Triandis, 1986; Yoneyama, 1976). 
Based on these three communicative differences, this study was designed to explore an aspect of Japanese selfdisclosure in relation to perceived social attraction. Using the concept of ingroup and outgroup relationships, this study examined the relationship between the level of verbal self-disclosure, in terms of verbal frequency and topic intimacy, and perceived social attraction in initial interaction between Japanese strangers.

In addition to extending the research on selfdisclosure outside of the United states, this study sought to provide more accurate information about current Japanese culture and communication styles by using a Japanese sample living in Japan. Within this context, the study examined self-disclosure, stranger-to-stranger interaction, and ingroup and outgroup relationships in interpersonal communication in Japanese culture.

\section{DEFINITION OF CONCEPTS}

The following four concepts were used in this study: self-disclosure, social attraction, ingroup and outgroup relationships, and initial interaction between strangers.

\section{Self-disclosure}

In general, self-disclosure is defined as the communication act or behavior which lets the self be known to the other (Bradac, Tardy, \& Hosman, 1980; DeVito, 1983; 
Jourard, 1958, 1971; Jourard \& Lasakow, 1958; Wheeless \& Grotz, 1976). This communication act is composed of both verbal and nonverbal communication behaviors. Bradac, Tardy, and Hosman state that "disclosure style comprises linguistic, paralinguistic, kinesic, and proxemic elements" (p. 228). For instance, saying " $I$ am a senior of $X$ University" reveals a speaker's educational background (a senior of $X$ University) and social status (a college student). At the same time, the speaker's nonverbal cues may convey something about him/her.

Eye contact, a fleeting touch, or a special smile may be used to communicate personal information in subtle and sometimes not so subtle ways (Derlega \& Chaikin, 1977, p. 103).

Thus, verbal and nonverbal behaviors simultaneously give information about the self to others in communication.

However, due to two methodological constraints of this study, only the verbal aspect of self-disclosure was focused upon. First, the researcher was living in the United States and did not have direct access to the Japanese based sample and their nonverbal responses to the research questionnaire. Second, the design of this study was sufficiently complex as to preclude testing both the verbal and nonverbal features of self-disclosure. Therefore, in this study, selfdisclosure was defined as a verbal communication act whereby a speaker conveys information about the self to the other that could not be available to the other unless told by the 
speaker him/herself. In this study, the level of verbal self-disclosure was determined by both verbal frequency and topic intimacy.

\section{Social Attraction}

Levinger (1974) defines attraction as "the positivity of one person's attitude toward another" (p. 100). McCroskey and McCain (1974) observe that interpersonal attraction is not unidimensional, but a multidimensional construct consisting of three dimensions: social, task, and physical. They state that social attraction is a socioemotional property of interpersonal attraction represented by "liking." Task attraction is a category "reflecting desirable features of working with a particular individual" (Grove, 1991, p. 33). Physical attraction concerns physical appearance (McCroskey \& McCain, 1974), and is related to the notion "what is beautiful is good" (Knapp, 1984, p. 141).

This study restricted its focus to the dimension of "social attraction" for two reasons. First, Grove (1991) maintains that task attraction becomes important in situations where individuals work together. Therefore, task attraction would not exist in a stranger-to-stranger interaction. Second, Grove goes on to say that physical attraction is the most crucial factor initially, but it is soon replaced by social attraction. Further, physical attraction did not fit within the focus of this study, which 
is verbal self-disclosure.

\section{Ingroup and Outgroup Relationships}

In Japanese culture, the group dominates the individual

in interpersonal relationships.

Groups in Japan are permanent and determinate. Individuals are temporary and have no existence, in theory, outside the group. This outlook does not negate the important functions and contributions of individuals within groups but it does subordinate the "self" to the group. Individual fulfillment of self is attained through finding and maintaining one's place within the group. If the group is successful, so is each part of it (Cathcart \& Cathcart, 1988, p. 187).

In Japanese society, each individual belongs to one or more specific groups depending on the situation and shows great loyalty toward them (Morsbach, 1976). The tie of group members is strong, and their relationships are based on interdependence among the members (Okabe, 1983).

Triandis (1986) claims that, in comparison with individualistic cultures such as the United States, collectivistic cultures, including Japan, draw a sharper distinction between ingroup and outgroup members in communication. Here, "ingroup members" mean individuals who belong to the same group in terms of social relationship categories such as family, school, and corporation (Gudykunst, Yoon, \& Nishida, 1987; Triandis, 1986). Outgroup members are individuals being outside of such ingroup relationships. Mizutani (1979) reveals that even in the initial encounter with a stranger, Japanese perceive 
whether or not the stranger is a member of their ingroup or outgroup, and hold different attitudes depending on the stranger's group membership.

In Japanese culture, ingroup formation is situational, and different ingroups are formed according to the context. "Japanese society is divided into numerous groupings, each structured along multiple status layers" (Okabe, 1983, p. 28). Ishida (1984) notes that, in traditional Japanese society, people belonged to many levels of ingroups. The family and extended family were the first and primary levels, next the hamlet, or a village, or a prefecture, and then the nation. In modern Japanese society, the family, school, corporation, clubs, sports teams, etc. become the group identification in the situation of the moment (Jorden \& Noda, 1987). Jorden and Noda point out the fluidity of ingroup formation:

The groups are constantly shifting, depending on the participants and the speaker's viewpoint. Group affiliation is so basic that it is probably valid to consider an individual who, at the moment, is operating in isolation, as a "minimal in-group" (p.164).

The above quotation applies to outgroup membership as well. As one moves out of a group in which he/she is considered a member of the group, he/she may be considered an outgroup member by that group. 


\section{Initial Interaction between strangers}

In Japan, the initial interaction between strangers occurs when person $Y$ and person $Z$ meet and talk for the first time. Even if $Y$ has seen $Z$ before, $Z$ is considered a stranger by $\mathrm{Y}$ as long as $\mathrm{Y}$ and $\mathrm{Z}$ have not been introduced to each other, Y has not talked to $Z$, or $Y$ does not know $Z^{\prime} s$ background well. For example, Yoneyama (1976) mentions that even if they see each other on the way to work every morning, Japanese would still regard each other as strangers. Nakane (1974) defines strangers in Japanese culture as people whose background is unknown.

Further, Mizutani (1979) contends that, for Japanese, greeting or speaking to the other is not used for relationship formation, but rather, is the means to ensure that they have already established a certain kind of relationship, and that the relationship is still working between them. Thus, Japanese rarely talk to strangers with whom they do not have any kind of relationships.

\section{HYPOTHESES}

The following hypotheses were constructed based on the literature review and tested in this study:

H1: For the ingroup members, the high discloser will be perceived to be more socially attractive than the low discloser.

H2: For the outgroup members, the low discloser will be perceived to be more socially attractive than the high discloser. 
OVERVIEW OF THE THESIS

Chapter I has presented the justification and purpose of the study, key concepts and hypotheses to be tested. Chapter II, an indepth literature review, provides the theoretical background of the study, including the concept of self-disclosure used in two theories which have been developed in the United States, and features of Japanese culture and communication relevant to the study. Chapter III describes the research methods including the sampling frame, sample, research design, measurement, and research procedures used in this study. Chapter IV presents the results of the data analyses, including the sample characteristics and measurement reliability. In Chapter V, the research findings are discussed as well as the study limitations, directions for future research, and conclusion. 


\section{CHAPTER I I}

\section{REVIEW OF THE LITERATURE}

This chapter consists of four sections. Section one outlines the theoretical background of the study of selfdisclosure used in Berger and Calabrese's (1975) uncertainty reduction theory and Altman and Taylor's (1973) social penetration theory. The second section discusses Japanese culture and communication drawing on Hall's (1976) high- and low-context distinction and Hofstede's (1980) individualismcollectivism dimension of cultural variability. The third section focuses on Japanese communication styles in interaction with a stranger. The final section discusses the assumptions about the relationships among the level of self-disclosure, group identification, and perceived social attraction in initial interaction between Japanese strangers. Based on these assumptions, two study hypotheses are proposed.

\section{SELF-DISCLOSURE AND COMMUNICATION}

\section{Self-disclosure}

Jourard $(1968,1971)$ argues that people have two needs related to self-disclosure. An individual wants to let the other discloses him/herself, and at the same time he/she 
wants to disclose him/herself to the other. According to Jourard, when people fulfill these two needs, they achieve mental health and positive relationships with others. Other researchers have suggested additional motivations for selfdisclosure. People disclose for catharsis, selfclarification, self-validation, reciprocity (feedback from others), impression formation, relationship maintenance and enhancement, social control, and manipulation (Adler, Rosenfeld, \& Towne, 1986). Also people disclose because they believe "that it is best to 'tell it like it is,' 'lay it on the line,' and 'reveal ourselves as we really are'" (Knapp, 1984, p. 209). These motivations are directed toward benefits associated with self-disclosure such as decreased self-alienation, increased consistency between self-concept and the other's concept of the self by reciprocity, and positive outcomes in interpersonal relationships with increased trust, liking, and attraction (Rosenfeld, 1979).

On the other hand, potential negative aspects are associated with self-disclosure. Self-disclosure may lead to rejection, negative self-image and self-evaluation, and a loss of self-esteem and esteem from the other. It may also lead to a decrease in the satisfaction of a relationship, a loss of social control over the other, or hurt the other by decreasing the other's self-esteem. Lying may have greater benefits than true self-disclosure in order to save face and 
avoid tension or conflict (Adler, Rosenfeld, \& Towne, 1986; Rosenfeld, 1979; Steele, 1975). Although people engage in self-disclosure, they may hesitate to reveal the self because of these perceived risks, which may in turn, reduce or dissolve their interpersonal relationships (Powell, $1969)$.

What factors, then, determine whether self-disclosure is positive or negative in communication? Self-disclosure is a multimodal phenomenon influenced by a variety of situational and environmental norms (Morton, Alexander, \& Altman, 1976). Adler, Rosenfeld, and Towne (1986) suggest seven criteria for self-disclosure. Before self-disclosing, people should consider whether the receiver is important to them, the risks carried by the self-disclosure are appropriate, the self-disclosure is relevant to the situation, the self-disclosure will be reciprocated, the effect will be constructive, and the content of the selfdisclosure is clear and understandable.

Similarly Knapp (1984) offers seven tips for effective self-disclosure. In order to achieve effective selfdisclosure, people want to consider the timing of the disclosure, the receiver's capacity to respond, the kind of relationship, long-term versus short-term effects, motives for the self-disclosure, how much detail is called for, and whether the disclosure is relevant to the situation and feelings. By proposing criteria for effective self- 
disclosure, Adler, Rosenfeld, and Town (1986) and Knapp suggest that self-disclosure is regulated by norms of reciprocity, relationship stage, and appropriateness in terms of intimacy, amount, type, timing, and situation. Violation of these norms can produce negative outcomes in interpersonal communication and relationships.

Two relevant theories inform the present study of selfdisclosure: Berger and Calabrese's (1975) uncertainty reduction theory and Altman and Taylor's (1973) social penetration theory. Both theories give self-disclosure the central importance in communication between strangers.

Berger and Calabrese's Uncertainty Reduction Theory

Berger and Calabrese (1975) divide the communication transaction stage into three phases: the entry, personal, and exit. According to them, the entry phase corresponds to the interaction between strangers, and "at the beginning of the entry phase uncertainty is relatively high" (p. 101). They focus on the entry phase and posit that "when strangers meet, their primary concern is one of uncertainty reduction or increasing predictability about the behavior of both themselves and others in the interaction" (p. 100).

In this theory, uncertainty represents the inability to predict and explain others' behavior in the interaction. In interaction with a stranger, there are so many alternatives for the stranger's behavior that, in order to choose his/her 
own appropriate behavior in response to the stranger' behavior, one must narrow the range of alternatives by predicting (proactive attributions) and explaining (retroactive attributions) the stranger's behavior (Berger, 1975; Berger \& Calabrese, 1975). Thus, uncertainty reduction in this theory means increasing the ability to predict and explain the stranger's behavior.

Berger and Calabrese (1975) propose seven axioms which suggest the relationships between self-disclosure and each of the following variables: amount of verbal communication, nonverbal affiliative expressiveness, information seeking behavior, intimacy level of communication content, reciprocity rate, similarity between persons, and liking. Concerning the relevant concepts to this study, the axioms contend that when uncertainty is high, the amount of verbal communication is low, and interactants seek more information about the other to reduce uncertainty. However, as uncertainty decreases, verbal communication increases and information becomes more personal. Also finding more similarities with others reduces uncertainty, and liking toward the other increases as uncertainty lowers.

Berger (1979) identifies three information-gaining strategies for dealing with uncertainty: passive, active, and interactive. Along with interrogation and deceptive detection, self-disclosure is identified as one of the interactive strategies used in direct communication with 
others. Berger maintains that self-disclosure is governed by the norm of reciprocity, in that, when one selfdiscloses, the other will return the same intimacy level of self-disclosure. The main concept here is that by using his/her own self-disclosure, the speaker can induce the same intimacy level of self-disclosure from the other. This strategy can be used for any intimate level of selfdisclosure. "Disclosure can beget disclosure of any number of different intimacy levels" (p.41).

Now we will turn to a second theoretical perspective relevant to the norms of self-disclosure; Altman and Taylor's (1973) social penetration theory.

\section{Altman and Taylor's Social Penetration Theory}

Altman and Taylor (1973) suggest that interpersonal relationships are formed through a developmental process represented by the increase in amount and intimacy level of self-disclosure. At the early stage of a relationship, the amount and intimacy level of self-disclosure is limited. As the relationship develops, more variety of topics are exchanged and the content of self-disclosure shifts from a superficial and nonintimate level to a more personal and intimate level.

Social penetration theory gives central importance to the concept of self-disclosure, hypothesizing that interpersonal exchange gradually progresses from superficial, nonintimate areas to more intimate, central areas of the actors in relationship (Gudykunst \& Nishida, 1983, p. 593). 
In other words, the positive progression of amount and intimacy level of self-disclosure indicates the relationship development from strangership to acquaintanceship, or even to a more intimate relationship.

Altman and Taylor (1973) propose four stages of relationship development: orientation, exploratory affective exchange, full affective exchange, and stable exchange. During the orientation stage, which corresponds to the initial interaction between strangers, impersonal and public information is exchanged. Altman and Taylor's theory is generally consistent with Miller and Steinberg's (1975) concept of three kinds of information: cultural, sociological, and psychological. Each kind of information is considered to reveal increasing personal information about the self as well as help to predict the other's action and guide behavior in response to it (Grove, 1991). "Social penetration, in these terms, is the process of moving from cultural interaction to psychological interaction" (Littlejohn, 1989, p. 187). According to Miller and Steinberg, at the first stage of relationships, cultural information represented by "a person's most generally shared cultural attributes, including language, shared values, benefits, and ideologies" (Littlejohn, 1989, p. 186) is exchanged between interactants.

The concept of self-disclosure and the foregoing two theories have been developed in U.S. culture. The next 
section discusses Japanese culture and communication using Hall's (1976) high- and low-context distinction and Hofstede's (1980) individualism-collectivism dimension of cultural variability.

\section{CULTURE AND COMMUNICATION IN JAPAN}

In general, interpersonal communication and relationships are governed by communication norms. As Altman and Taylor (1973) observe:

There are norms about invasion of privacy, rules of decorum, implicit guides to avoid noticing the foibles of others, extended courtship concepts, socially approved modes of response which protect the individual from exposure, and sanctions against those who violate the norms of gradual designed to pace the process of interpersonal exchange. Were there no such controls, interpersonal relationships would be unpredictable and volatile (pp. 134-135).

Such norms are not universal, but are culturally distinctive and taught to members of the culture through acculturation.

Through acculturation every culture teaches its members distinctive norms to follow in what should be talked about and what should not, when it should be discussed, and with whom and at what rate one should share confidences with a companion (Barnlund, 1989, p. 108).

Further, communication norms are featured by cultural variability. Ting-Toomey (1989) maintain:

Dimensions of cultural variability influence the underlying social structures and norms of a situation, and the social norms, in return, influence how one should or should not behave in a certain manner ( $p, 352)$.

Thus, cultural variability should be considered when 
studying interpersonal communication in the different cultural contexts.

Acknowledging the concept of cultural variability and its influence on communication norms, several researchers (e.g., Gudykunst, 1989; Gudykunst \& Nishida, 1986; Gudykunst \& Nishida, 1983; Gudykunst, Nishida, Koike, \& Shiino, 1986) have extended the communication theories developed in the United States to Japanese culture. In general, Hall's (1976) high- and low-context distinction and Hofstede (1980) and others' (Hofstede \& Bond, 1984; Triandis, 1986) individualism-collectivism dimension of cultural variability are used to characterize the differences between Japanese and U.S. culture. These two dimensions define Japan as a high-context and collectivistic culture and the United States as a low-context and individualistic culture. Based on the high- and low-context distinction and individualismcollectivism dimension, the present study provides characteristics of Japanese culture and communication relevant to the study, that is, verbal communication and ingroup and outgroup relationships.

Verbal Communication in High-context Culture According to Hall (1976), members of high-context cultures such as Japanese depend on the physical context or internalized information in the person to interpret messages, and very little of the message is coded, that is, 
explicit, or transmitted in actual verbal communication. On the other hand, members of low-context cultures, including the United States, depend on the explicit verbal code to communicate with each other. Hall goes on to say:

People raised in high-context systems expect more of others than do the participants in low-context systems. When talking about something that they have on their minds, a high-context individual will expect his interlocutor to know what's bothering him, so that he doesn't have to be specific. The result is that he will talk around and around the point, in effect putting all the pieces in place except the crucial one. Placing it properly this key stone - is the role of his interlocutor (p. 113 ).

In high-context cultures, communication is based on the assumption that interactants share the same contextual information. For instance, Hall explains that, in verbal communication, the speaker uses indirect and ambiguous expression and leaves the point unclear because the listener is expected to know what is going on at the covert level. If the listener does not know what he/she is supposed to know, the speaker will be upset and communication will be interrupted.

Principles of Japanese communication forms which focuses on the implicit codes is strongly influenced by Japan's historical background. Morsbach (1976) contends that Zen Buddhist teaching of the Kamakura era (1185-1333) strongly influenced Japanese culture in which great value was placed on silence and language was replaced by nonverbal cues. The main concept of Zen is "kan," which can be 
translated as "perception," "institution," or " the sixth sense," and people are expected to get "satori" ("enlightenment") not by talking about it, but by using their "kan."

In addition, the Tokugawa shogunate's (1603-1867) policy of "the cutting off from the outside world" and the geographical isolation allowed Japan to avoid invasions from outside countries and develop a homogeneous culture in race and language. As a result, Japan could develop the "endogamous society" (Kunihiro, 1976) in which people shared a great many aspects of daily life and consciousness, and communication was based on the commonality of thinking or feeling patterns with others. In comparison with those of Western, Eto (cited in Barnlund, 1989) summarizes Japanese communication styles:

In other words, whereas Western base their lives on the premise that others naturally feel differently about things and view things according to different principles, the Japanese take it for granted in their daily lives that other people feel and think the as they do themselves (p. 116).

According to Morsbach (1976), in the Tokugawa period "keeping quiet became a virtue, and since most things in daily life were tightly regulated anyhow, language could be amplified, changed, or replaced by nonverbal communication" (p. 242 ).

Influenced by its historical and, in part, geographical background, Japan has developed a culture in which oral 
skills are not highly valued in interpersonal communication (Kang \& Pearce, 1983; Klopf \& Cambra, 1979; Okabe, 1983). Instead of verbal communication, Japanese emphasize nonverbal communication and use indirect communication forms such as silence and reading the other's mind by using mental "telepathy" (Morsbach, 1976; Okabe, 1983; Tsujimura, 1987). The mental "telepathy," which Tsujimura calls "ishindenshin," is a mind-to-mind communication without using language and depends on individuals, "sasshi" ("guess") competence in communication. Tsujimura goes on to say that because of this communication form, Japanese communication occurs "when nothing is said" (p. 117). Therefore, Japanese consider silence as meaningful, and do not hesitate to let long silences be. They perceive that "breaking silence is a necessary evil, at best" (Ishii \& Bruneau, 1988, p. 310).

In Japanese culture, talkativeness or verbosity is negatively evaluated and leads to mistrust or suspicion, while quietness leads to the notion of trustworthiness, thoughtfulness, and maturity (Kindaichi, 1975; Mizutani, 1979; Okabe, 1983; Yoshikawa, 1978). Barnlund (1975), using an example of the Japanese traditional huge paper carp streamers, notes:

There appears to be strong cultural resistance to excessive verbalization and a compensating reverencing of silence and less explicit forms of expression. Many Japanese aphorisms reflect this cultural attitude. Talkative persons, for example, are characterized as resembling a "paper carp in May." Like these inflated banners, talkative people consist only of huge open mouths with nothing but air inside ( $p .81)$. 
Similarly, Kindaichi explains that Japanese tend to look down on eloquent people because they consider that eloquence is used as a verbal excuse by those who do not have actual executive ability. Kindaichi offers examples in which some eloquent individuals in Japanese history could not achieve the higher social status because of their eloquence.

Ishikawa's (cited in Ishii \& Bruneau, 1988) study of Japanese business people reveals that the Japanese subjects consider men's success in life is achieved by being "silent," and that $65 \%$ of the Japanese female subjects would prefer to choose a "silent" man for husband. Further, Ishii and Klopf (cited in Barnlund, 1989) compared the length of conversation in which Japanese and Americans engage. They found that "Japanese spent roughly three and a half hours a day in conversation while Americans spent nearly seven hours, or twice as long, talking with their acquaintances" (pp. 115-116). The results of the two studies show that in Japanese society, quietness receives more positive evaluation, and the rate of verbal communication is lower than in the United States.

As noted above, in Japanese culture, communication competence is not judged by the verbal ability. Instead, it is judged by the ability to adapt to the situation and behave appropriately to the situational demands, the ability to accurately discern the relationship level of communication from its context (Iritani, 1971; Nakanishi, 
1986), and the ability to understand and interpret the implicit meaning in indirect expression from the situational context (Okabe, 1983).

Focusing on interpersonal relationships, Hof stede's (1980) individualism-collectivism dimension further helps to explain communication in Japanese culture.

\section{Interpersonal Relationships in Collectivistic Culture}

Hui and Triandis (1986) refer to individualismcollectivism dimension as the "cluster of attitudes, beliefs, and behaviors toward a wide variety of people" ( $p$. 240). Hofstede and Bond (1984) claim that whereas in individualistic cultures such as the United States "people are supposed to look after themselves and their immediate family only," in collectivistic cultures including Japan "people belong to in-groups or collectivities which are supposed to look after them in exchange" (p.419). A difference between individualistic and collectivistic cultures is the emphasis on the concept of "group." Compared with members of individualistic cultures, members of collectivistic cultures tend to form groups, and their communication patterns are based on interdependence with other members of those groups.

Ting-Toomey (1989) compares individualistic and collectivistic cultures by using the "I" and "we" identity: 
Overall, members of the individualistic cultures (such as Australia and the United states) tend to place a high emphasis on the "I" identity over the "we" identity, the "I" assertion over the group assertion, and tend to maintain a considerable social distance between the "I" identity and ingroup social influences. Conversely, members of the collectivistic cultures (such as China and Japan) tend to place a high premium on the "we" identity over the "I" identity, the individualistic assertion, and tend to be more susceptible to ingroup influences than members in the individualistic cultures. (pp. 352-353).

While individualistic cultures are individual- or "I"centered and emphasize the individuals' goals, collectivistic cultures are group- or "we"-centered and seek the group's, to be precise, the ingroup's goals. To achieve the group's goals, in ingroup relationships, Japanese tend to restrain their individual identities and give priority to the group identity by conforming themselves to other group members. Barnlund (1989) contends:

Individuals are taught to see how sensitively they can mesh their lives with those around them, particularly within the primary groups to which they belong (p. 115).

Also Okabe (1983) maintains that "the Japanese insist upon the insignificance of the individual" (p. 26).

The main concept of ingroup relationships is "harmony" based on interdependence among group members (Okabe, 1983; Cathcart \& Cathcart, 1988; Gudykunst \& Nishida, 1984; Reischaure, 1988). This concept comes from Confucianism which had been adapted as the official philosophy of the Tokugawa shogunate (1603-1867) and emphasized humanism and 
social relationships (Yum, 1988). "Harmony" is achieved by a "subtle process of mutual understanding, almost by institution" (Reischaure, 1988, p. 136). In order to maintain harmonious relationships among group members, Japanese avoid assertiveness, direct expression of feelings, and confrontation which might have negative effects on harmonious relationships (Nakane, 1974; Okabe 1983). Reischaure notes:

Cooperativeness, reasonableness, and understanding of others are the virtues most admired, not personal drive, forcefulness, and individual selfassertion (p. 136).

These collectivistic features of Japanese interpersonal communication contrast to the American value of individualism in that self-assertion and frank expression of opinions are encouraged and argumentation is required when challenged (Okabe, 1983). Okabe points out that in U.S. culture the value of independence is predominant, and "each individual is solely responsible for his for her own fate. What others think and say is of little significance" (P.25). On the other hand, Japanese culture emphasizes interdependence among group members and "what others think and say is of great importance than what the individual does" (p. 26). Thus, Japanese restrict displays of feelings and opinions. Further, in ingroup relationships, reciprocal obligation and harmonious equality are encouraged among group members (Nakane, 1974; Okabe, 1983). 
Triandis (1986) suggests that, in comparison with members of individualistic cultures, members of collectivistic cultures draw sharper distinctions between ingroup and outgroup members, and perceive ingroup members to be more intimate than outgroup members. This concept is consistent with Hall's (1976) definition of high-context cultures, in that, "high-context cultures make greater distinctions between insiders and outsiders than low-context cultures do" (p. 113). Although members of individualistic cultures tend to be universalistic and apply the same value standards to every individual, members of collectivistic cultures tend to be particularistic and apply different value standards to members of the ingroup and outgroup (Gudykunst, Yoon, \& Nishida, 1987).

Maruyama (1961) characterizes Japan and the U.S. respectively as the inward and outward cultures. He argues that in Japanese culture the only true communication and information exchange may be observed within a single cubicle (inward), that is, ingroup relationships, while in U.S. culture communication and information are exchanged in diverse branches (outward), outgroup relationships. Aida (1972) differentiates communication patterns of Japanese and Americans by using the terms "omote" ("exterior" or "outside") and "ura" ("interior" or "inside"). The "omote" is public, formal and conventional, and the "ura" is private, informal, and unconventional. He suggests that 
there is no distinction between the "omote" and "ura" in U.S. communication. Rather, the "omote" is dominant and it is always taken at face value. On the other hand, in Japanese communication, there is a clear distinction between the "omote" and "ura," and the "ura" is perceived to be more real and more meaningful than the "omote." As Okabe (1983) observes:

This tendency of the Japanese to distinguish between the omote and ura aspects of culture is closely related to their inclination to make the sharp discrimination between belongers to (or "ins" of) a given takotsubo group and outsiders (or "outs") (p. 25).

Thus, the "ura" is mainly used for communication with ingroup members and the "omote" for communication with ingroup members.

As an example of the distinction of ingroup and outgroup relationships in communication in Japanese culture, Okabe (1983) explains that "at national and international levels, all foreigners are lumped together as 'gaijin' (literally 'outsiders') and treated as such" (p. 25). Further, Jorden and Noda (1987) claim that Japanese language requires speakers to use different forms to address to people belonging to their ingroups and outgroups. For example, within the ingroup of the company, the subordinates refers to their boss in polite language, but when they are interacting someone from another company (an outgroup member), they do not refer to their boss (an ingroup member) 
in polite language. In interaction with outgroup members, Japanese tend to be humble in reference to ingroup members in order to show politeness to outgroup members.

Nakane (1974) maintains that while Japanese hold a strong relationship bond with other ingroup members, they are indifferent to outgroup members. Gudykunst, Yoon, and Nishida's (1987) study revealed that there was greater amount of personalization and synchronization, but less. communication difficulties among ingroup members in collectivistic cultures including Japan and Korea. Based on this result, Gudykunst (1989) posits:

Members of collectivistic cultures perceive greater social penetration (more personalization and synchronization, but less difficulty) in ingroup relationships than do members of individualistic cultures (p. 328)

On the other hand, there are "relatively low level of personalization and synchronization in communication with members of outgroups" (p. 329).

\section{Self-disclosure in Japanese Culture}

Using a modification of Jourard and Lasakow's (1958) self-disclosure scale, Barnlund (1975) compared the preferred topic, the preferred target person, and the depth of self-disclosure between Japanese and Americans. He found that Japanese preferred to talk about matters of interest or taste, opinions about public issues, and attitudes toward work or studies, but they ranked financial matters, aspects 
of personality, and feeling about pone's body lower. American respondents also reported similar topic choice. As the most communicative partner, Japanese chose friends and then parents, and they ranked strangers and untrusted acquaintances last. Americans showed the similar order of the preferred partners.

However, differences between Japanese and Americans appeared in the average score of self-disclosure level across all topics and all target person. The average score of self-disclosure level for Americans was almost 1.5 times that for Japanese. Based on these results, Barnlund (1975) suggests that, compared with Americans, Japanese posses a smaller "public self," which stands for "the self accessible to others through communication" (p. 80), and a greater "private self," which is represented by the unwillingness to talk about the self to others. This is reflected in Japanese verbal communication patterns described by Guillain (cited in Barnlund) as Japanese enjoy social contacts, but "beyond polite phrases, the Japanese speaks very little, particularly about himself" (p. 81). Barnlund attributes the results of his study that Japanese have greater private self and smaller public self and keep greater interpersonal distance with others than Americans to "strong cultural resistance to excessive verbalization and a compensating reverencing of silence and less explicit forms of expression" (p. 81). 
In his second study using the Barnlund-Campbell Dimensions of Interpersonal Relations scale, Barnlund (1989) found similar results to his first $1975^{\prime}$ 's study. Barnlund states that "the Japanese tend to be more formal and restrained, less talkative and revealing themselves," while Americans are less formal and more assertive, more talkative and expressive of themselves" (p. 118). Barnlund proposes that problematic consequence for cross-cultural encounter of Japanese and Americans would be:

The Japanese are likely to feel embarrassed with what appears to be invasions of their privacy, the Americans equally embarrassed by the indirectness and formality of the Japanese (p. 119).

Barnlund argues that the differences in the level of selfdisclosure are caused by the difference in interpersonal distance represented by "private and public self" between Japanese and Americans.

The foregoing section discussed the general characteristics of Japanese culture and communication. Focusing on the interaction with a stranger, the next section provides Japanese communication styles in terms of verbal communication, interpersonal relationships, and selfdisclosure. 
COMMUNICATION BETWEEN STRANGERS IN JAPANESE CULTURE

In general, Japanese are more reluctant to interact with individuals whose background is unknown, that is, strangers (Barnlund, 1989; Nakane, 1974). Yoneyama (1976) offers an example in which Japanese apparently take different attitudes toward strangers and individuals whose background is known.

In the train, a middle-aged woman occupied the seat for more than one person, ignoring an old woman standing beside her. As soon as she saw her acquaintance getting on the train, she turned her face into smiles and started offering the seat to the acquaintance, saying "please have a seat, please" (p. 9).

In this example, not age, but whether the old woman is a stranger is the most important factor for the middle-aged woman to offer the seat. Further, the results of Barnlund's (1975) study about the preferred target persons for selfdisclosure and the level of self-disclosure revealed that, although both Japanese and Americans perceive strangers and untrusted acquaintances as the least favored partners for self-disclosure, the scores for all target persons were substantially higher with Americans than with Japanese. Barnlund's study results imply that, in comparison with Americans, Japanese are less willing to disclose to strangers.

Thus, Japanese rarely socially interact with strangers. However, supposing that a stranger-to stranger interaction 
can occur in some situations, some researchers suggest characteristics of Japanese communication styles in interaction between strangers.

\section{Verbal Communication between Strangers}

In high-context cultures, the situational context has a great influence in communication (Hall, 1976). Therefore, in interaction with a stranger, it is important to predict "the degree to which strangers will follow the social norms prescribed in the context" (Gudykunst, Nishida, Koike, \& Shiino, 1986, p. 571). Nakane (1974) argues that when they interact with a stranger, Japanese engage in the stranger's background information seeking behavior to increase their attributional confidence about the stranger's future behavior. This is consistent with Hall's definition of high-context culture in which members of high-context culture make more assumptions about strangers based on their cultural background.

Maruyama (1961) proposes that in Japanese culture "what he/she is" is more important than "what he/she does." Similarly, Okabe (1983) notes that "an individual's birth, family background, age, and rank tend to be more important than his or her later achievement and development" (p. 24). In this cultural frame, Japanese communication is distinctive by age, gender, and social status or role (Condon, 1977; Yoneyama, 1976). Therefore, background 
information represented by age, gender, and social status or role provides information necessary to increase attributional confidence about the stranger's future behavior (Gudykunst, 1983; Nakane, 1974).

In addition, social background information also specifies "how to talk with strangers (i.e., it tells them how to address strangers and which forms of the language to use)" (Gudykunst \& Nishida, 1986, p. 529). Therefore, Japanese speakers are not sure how to communicate "until they know the status of the other person since the language requires different forms to correspond to the status of the listener" (Stewart, 1971, p. 50).

\section{Interpersonal Relationships between Strangers}

Although Japanese rarely interact with a stranger, if they perceive a stranger to be their ingroup member, Japanese may talk to the stranger. Mizutani's (1979) research revealed that even in a short encounter Japanese identify a stranger to be a member of their ingroup or outgroup, and talk to a stranger perceived to be an ingroup member. In his research, Mizutani used "jogging" as a factor to distinguish ingroup and outgroup members. While jogging around the Imperial Palace in Tokyo, Mizutani greeted both jogging and non-jogging strangers on the street. More than $95 \%$ of joggers responded to the researcher in some way, while less than $43 \%$ non-joggers 
responded. These results indicate that even in the initial interaction with a stranger, Japanese distinguish their ingroup and outgroup members and show more intimate attitudes to ingroup members than outgroup members in communication.

\section{Self-disclosure between Strangers}

Using a sample of Japanese native speakers, Nakanishi (1986) investigated the relationship between self-disclosure and logical force, episode perception social attraction, and communication competence in initial interaction between Japanese strangers. The results of his study indicate differences in the concept of self-disclosure between Japan and the United States. First, for Japanese respondents "self-disclosure did not determine the degree of openness, friendliness, or intimacy perceived in the dialogue" ( $p$. 183). This result is not consistent with the findings of studies conducted in the United States (e.g., Jourard, 1959; Wheeless, 1976), in which, in a stranger-to-stranger encounter, self-disclosure is closely related with such concepts as openness, intimacy, closeness.

Second, Japanese females felt more comfortable in the low disclosure conversation and evaluated the high disclosure conversation more negatively than did males. In some U.S. studies le.g., Eakins \& Eakins, 1978; Jourard, 1971), females were found to be higher disclosers than 
males. On the other hand, Nakanishi's (1986) study revealed that Japanese females considered high self-disclosure to be less useful and important in social interaction than did males.

Third, the high discloser was perceived to be less socially attractive than the low or moderate self-discloser. Nakanishi (1986) concludes that this finding is generally consistent with U.S studies (Cozby, 1972; Davis \& Sloan, 1974; Mann \& Murphy, 1975) which found that moderate selfdisclosure was perceived to be more liked than high or low self-disclosure. However, Barnlund's (1975, 1989) findings about differences in the level of self-disclosure between Japanese and Americans suggest that it cannot be easily concluded that Americans and Japanese perceive the same level of self-disclosure in the same way. In addition, Nakanishi's finding is contrasting to the U.S. studies in a point that Japanese perceived low self-disclosure to be more attractive as well as moderate self-disclosure, while Americans perceived low self-disclosure negatively. Further, Nakanishi found that Japanese perceived the high discloser to be the least competent communicator, while evaluated the low discloser most positively.

Based on foregoing features of Japanese culture and communication and the theories developed in the United States, the final section discusses the assumptions which lead to formation of two hypotheses about the relationship 
among the level of self-disclosure, group identification, and perceived social attraction in initial interaction between strangers in Japan.

\section{ASSUMPTIONS ABOUT INITIAL INTERACTION BETWEEN JAPANESE STRANGERS}

First, in general, in initial interaction between Japanese strangers, the high level of self-disclosure, that is, high verbal frequency and topic intimacy of selfdisclosure will be negatively evaluated, and thus lead to less perceived social attraction. High verbal frequency is counter Japanese cultural norms in that talkativeness or verbosity are not highly valued because it leads to mistrust or suspicion, while quietness leads to the notion of trustworthiness, thoughtfulness (Barnlund, 1975; Condon, 1977; Kang \& Pearce, 1983; Kindaichi, 1975; Klopf \& Cambra, 1979; Mizutani, 1979; Okabe, 1983; Yoshikawa, 1978). Further, high verbal frequency displays self-assertiveness and may violate harmonious relationships (Johnson \& Johnson, 1975; Kindaichi, 1975; Mizutani, 1979; Nakane, 1974; Okabe, 1983 ; Yoshikawa, 1978).

In addition, high topic intimacy of self-disclosure is contradictory to situational and relationship demands. Japanese rarely have contact with strangers (Barnlund, 1975, 1989; Nakane, 1974; Yoneyama, 1976). When they interact with a stranger, Japanese will engage in nonintimate self- 
disclosure such as the stranger's background information seeking to increase attributional confidence about the stranger's future behavior, but not seek the stranger's personal information (Altman \& Taylor, 1973; Berger \& Calabrese, 1975; Gudykunst, 1983; Nakane, 1974). Thus, in initial interaction between Japanese strangers, the high level of self-disclosure may be perceived as violation of communication norms. On the other hand, the low level of self-disclosure will be perceived to be more appropriate to the norms, and lead to more perceived social attraction.

Second, in the interaction with a stranger, if Japanese identify the stranger to be an ingroup member (i.e., they graduated from the same school, or they will work at the same company), perceived social attraction will increase and the level of self-disclosure will also increase. Berger and Calabrese's (1975) uncertainty reduction theory suggests that finding similarity with the other will reduce uncertainty, and that as uncertainty decreases, the amount of verbal communication will increase. Further, identifying the stranger as an ingroup member will increase social penetration (Gudykunst, 1989) and the content of selfdisclosure will move into more intimate level (Altman \& Taylor, 1973). Aida (1972) states that with a person who is perceived to be an insider Japanese easily reveal their secrets to each other as if they were old friends, but those secrets will never be revealed to outsiders. 
Third, if Japanese identify the stranger to be an outgroup member, perceived social attraction as well as the level of self-disclosure will not increase as much as in the interaction with a stranger identified as an ingroup member. They will seek the stranger's background information to reduce their uncertainty and increase their attributional confidence of the stranger's future behavior (Altman \& Taylor, 1973; Berger \& Calabrese, 1975; Nakane, 1974). Japanese do not feel outgroup members as intimate as ingroup members (Hall, 1976; Triandis, 1986; Yoneyama, 1976) and have low level of social penetration with outgroup members (Mizutani, 1979; Gudykunst, 1989). Thus, compared with the interaction with a stranger identified as an ingroup member, their verbal frequency will be lower and they will not exchange personal information with each other. In light of these assumptions, two hypotheses were formulated and tested in this study.

H1: For the ingroup members, the high discloser will be perceived to be more socially attractive than the low discloser.

H2: For the outgroup members, the low discloser will be perceived to be more socially attractive than the low discloser. 


\section{CHAPTER III}

\section{METHODS}

This chapter describes the methods employed in this study, including the sampling frame, sample, research design, measurement, and research procedures, which includes the translation procedure, pilot study, and data collection procedure.

\section{SAMPLING FRAME}

The purpose of this study was to extend the study of self-disclosure beyond the United States and examine selfdisclosure as it occurs between native Japanese speakers in the Japanese cultural context. For this purpose, the sampling frame was Japanese college students in Japan, not Japanese students currently staying in the United states.

It was assumed that Japanese students living in the United States would be influenced more or less by U.S. culture and that their communication patterns might change through interaction with Americans. Their communication behavior would likely differ to some extent from that of Japanese who had had less direct exposure to U.S. culture. In addition, the degree to which each student was influenced by U.S. culture might vary. Nakanishi (1986) points out the 
limitations of intercultural or cross-cultural studies using students or minority ethnic groups in the United states:

Although this kind of approach is an acceptable way of studying communication cross-culturally, researchers need to take special precautions against the possible confounding of the results due to the process of "acculturation" (Kim, 1979) and varied degrees of English proficiency among subjects (p. 168).

Thus, for the purpose of this study, drawing the sample from Japanese students in the United States was not appropriate. In order to circumvent the limitations noted above, the study sampling frame consisted of native Japanese speaking college students who were currently living in Japan and had had limited exposure to U.S. or other Western cultures. Strictly speaking, college students are not representative of all Japanese who are currently living in Japan and have had limited exposure to Western cultures. However, as Nakanishi (1986) maintains:

the young generation is an important segment of any society and may be more sensitive to the contemporary values of the culture than the older generation. In addition, the use of the collegeage population increases the comparability of the results to studies conducted in the United States that are largely based on a similar type of sample (p. 173).

Further, college students were more readily accessible for the present study. Therefore, this study drew its sample from the population of Japanese college students living in Japan . 
SAMPLE

The sample consisted of 328 Japanese graduate and undergraduate college students selected from 11 English classrooms at three universities in the Kansai area in Japan. All subjects were born and raised in Japan, had studied English at least six years at junior high and high school levels, and had some knowledge about U.S. and other Western cultures through mass communication and English or other foreign language education classes.

\section{RESEARCH DESIGN}

In this study, the discloser's level of self-disclosure (high/low), which consisted of both verbal frequency and topic intimacy, was treated as the independent variable. The discloser's group identification (ingroup/outgroup) was the intervening variable. Perceived social attraction for the discloser was the dependent variable. Figure 1 illustrates the relationship among the three variables.

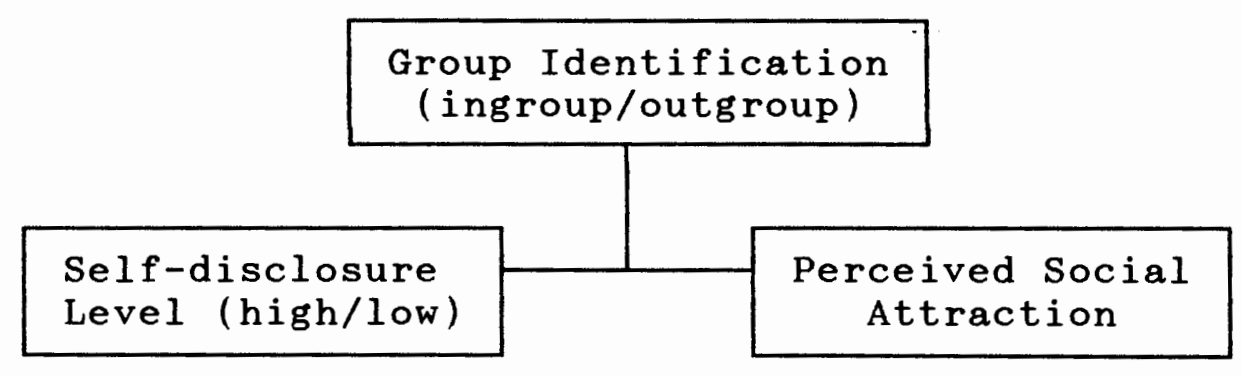

Figure 1. Relationship among the three variables. 
This study employed a $2 \times 2$ (Level of Self-disclosure $x$ Group Identification) factorial design, with four betweensubjects factors. Figure 2 describes this $2 \times 2$ design.

Group Identification

\section{Level of}

Self-disclosure

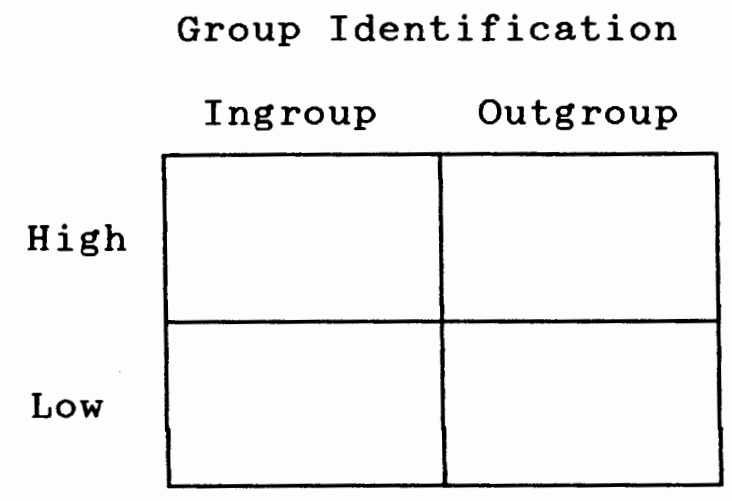

Figure 2. $2 \times 2$ factorial design.

In Figure 2, the vertical line represents the discloser's level of self-disclosure (high/low), and the horizontal line represents the discloser's group identification (ingroup/outgroup).

\section{MEASUREMENT}

\section{Questionnaire}

This study was an experiment based on role playing. The purpose of this study was to examine self-disclosure as a communication act in Japanese culture, and the sample consisted of native Japanese speakers who were currently living in Japan and had had limited exposure to Western cultures. Since the researcher was residing in the United States, in order to facilitate data-gathering at a distance 
and to assure uniform presentation within each condition, conditions of the discloser's level of self-disclosure and group identification were presented in scenarios and subjects' responses were obtained by questionnaire.

\section{Scenarios}

Eight scenarios were constructed to give the Japanese subjects a situation in which the initial interaction occurred with a male or female stranger (see Appendix A). The role playing method was chosen for three reasons. First, by providing each subject with one of the eight scenarios in which eight different types of disclosers were described, each subject was given a single condition to respond to. Second, interaction between strangers rarely occurs in Japanese society (Barnlund, 1975, 1989; Mizutani, 1979; Nakane, 1974; Yoneyama, 1976). It was expected that the Japanese subjects would find it easier to answer the questionnaire based on the scenario than based on their experience of interaction with a stranger. Third, the scenario would likely produce a more concrete image of an interaction with a stranger than relying on the subjects' recall.

To test the possibility that the subjects would react differently to the disclosers of the same and opposite gender, gender of the discloser was included in the discloser's condition as well as the discloser's level of 
self-disclosure and group identification. Thus, a total of eight scenarios were constructed. Figure 3 characterizes each discloser in the eight scenarios.

\begin{tabular}{|c|lll|}
\hline Scenario & \multicolumn{3}{|c|}{ Discloser } \\
& Level & Group & Gender \\
\hline 1 & high & ingroup & male \\
2 & low & outgroup & male \\
3 & high & ingroup & male \\
4 & low & outgroup & male \\
5 & high & ingroup & female \\
6 & low & outgroup & female \\
7 & high & ingroup & female \\
8 & low & outgroup & female \\
\hline
\end{tabular}

Figure 3. Eight disclosers in the eight scenarios.

In each scenario, the subjects were asked to take the hypothetical role of the listener in a conversation with a stranger under one of the foregoing eight conditions. The subjects gave yes or no answers or short responses to the discloser with whom they hypothetically interacted in the scenario.

No specific criteria were found in the literature that clarified the level of topics for self-disclosure in Japanese culture. For this study, the researcher selected topics for high and low self-disclosure according to criteria of uncertainty reduction theory, social penetration theory, intercultural and intracultural studies in Japanese culture on the foregoing theories, and Barnlund's (1975) study which investigated the favored topics in interaction 
between Japanese strangers.

In the scenarios of this study, the low discloser's utterances were limited to questions about the listener's (i.e., the study subjects') background, mainly educational background, and each utterance was short. On the other hand, in addition to asking about the listener's educational background, the high discloser talked about his/her own educational background and relationship with his/her spouse or girl/boy friend. The high discloser received no reciprocal utterances from the listener in terms of verbal frequency and topic intimacy.

This study focused on age and social status or role to determine whether the discloser in the scenarios was an ingroup or outgroup member. In Japanese culture, age and social status or role have great value in interpersonal relationships (Barnlund, 1989; Condon, 1977; Yoneyama, 1976), and ingroup formation is based on such social relationship categories as family, school, and corporation (Jorden \& Noda, 1987; Gudykunst, Yoon, \& Nishida, 1987). In addition, Gudykunst and Nishida's (1986) study found that Japanese perceive a relationship with people from their university or people with whom they work to be more intimate than do Americans.

In this study, the subjects were undergraduate and graduate college students. Considered that, in the Japanese school system, college students are usually not employed and 
range from 18 to 24 years old, it was expected that the subjects would perceive college students to be their ingroup member, and individuals of a different social status or generation to be their outgroup member. Thus, in the scenarios, the ingroup discloser was characterized as a student of the same school and about the same age (from 18 to 24 years old) as the subjects. The outgroup discloser was characterized as an employed individual in his/her thirties. Each subject was given a scenario and then asked to answer a set of 20 items based on the scenario.

\section{Scales}

The scale was constructed partly based on McCroskey and McCain's (1974) interpersonal attraction scale. The original McCroskey and McCain's Likert-type scale consisted of 30 items, 10 for each of the three dimensions of interpersonal attraction: social, physical, and task, and scored on a seven-point scale ranging from strongly agree to strongly disagree. Five items of each dimension were positively worded and the other five were negatively worded, and then the 10 items for each dimension were randomly ordered.

For the purpose of this study, only the 10 items of the social attraction dimension were selected from McCroskey and McCain's (1974) original scale, with 10 new items related to social attraction, the Sugita's social attraction scale, 
constructed by the researcher. Five of the 10 new items were related to the context of Japanese culture, while the other five were not culture-specific. Five of the new items were positively worded, the other five negatively worded, and then the 10 items randomly ordered. Thus, the final questionnaire consisted of a total of 20 items in two scales of social attraction (see Appendix B).

As noted above, in McCroskey and McCain's (1974) original study, each question was answered using a sevenpoint scale ranging from strongly agree to strongly disagree. However, in this study, to avoid the potential clustering of responses at the neutral midpoint by the subjects, the neutral midpoint of the scale was purposely deleted (see p. 51). A six-point scale, ranging from strongly agree to strongly disagree, was used for each of the 20 items.

For the positively-worded 10 items, the strongly-agree point was scored as 6 and the strongly-disagree point was scored as 1 (i.e., strongly agree $=6$, moderately agree $=5$, agree $=4$, disagree $=3$, moderately disagree $=2$, and strongly disagree $=1$ ). For the negatively-worded 10 items, the strongly-disagree point of the scale was scored as 6 and the strongly-agree point was scored as 1 (i.e., strongly disagree $=6$, moderately disagree $=5$, disagree $=4$, agree $=$ 3 , moderately agree $=2$, and strongly agree $=1$ ). Total scores of the 20 items were computed as perceived social 
attraction for the discloser. Higher total scores represented higher perceived social attraction, and lower total scores reflected lower perceived social attraction for the discloser.

\section{RESEARCH PROCEDURES}

\section{Translation Procedure}

The original questionnaire was constructed in English, and then translated by the researcher into Japanese. Translating the questionnaire was based on the assumption that since their native language was Japanese, the subjects would more likely understand the questionnaire accurately in Japanese than in English. A questionnaire written in English might interfere with the subjects' comprehension of the content, due to the translation process from English to Japanese when filling out the questionnaire. External review of the translated questionnaire was provided by a native speaking Japanese instructor currently teaching Japanese in the Foreign Language Department at Portland State University.

\section{Pilot Study}

"A pilot will reveal trouble areas: defects in the design, execution problems, experimenter mistakes, to mention but a few" (Tucker, Weaver II, \& Berryman-Fink, 1981, p. 144). In order to check any difficulties in the 
questionnaire and the research design prior to the actual research, a pilot study was conducted with eight Japanese ESL students enrolled at Portland State University who had come to the United States within the past six months. They were chosen based on the assumption that they would be less influenced by U.S. culture than other Japanese students who had lived much longer in the United States.

The purpose of the pilot study was to check whether the content of the translated questionnaire was understandable, whether the scale was easy to administer, whether the time required for completing the questionnaire was appropriate, and whether the research method fit the purpose of this study. In the pilot study, each of the eight Japanese subjects was asked to complete the translated questionnaire using a seven-point scale. After filling out the questionnaire, each subject was interviewed by the researcher to obtain reactions to the instrument. In the session, the subjects pointed out ambiguous Japanese words and phrases in the questionnaire. Their suggestions were later incorporated into the instrument. Difficulties in answering the questions using the Likerttype scales were also discussed. The Japanese subjects revealed that they tended to check the neutral point without thinking about the content of questions when they were not willing to answer the questionnaire or when they got tired of answering the questionnaire. In order to avoid the 
potential clustering of responses at the neutral midpoint, the neutral midpoint was deleted resulting in a six-point scale being used for each question in this study.

\section{Data Collection Procedure}

The researcher contacted three instructors of English teaching at three universities in Japan and asked for their participation and cooperation in the research process (see Appendix C). At the same time, the researcher contacted three universities in Japan at which the three instructors were teaching, and asked for official permission to conduct the study in the three instructors' classrooms (see Appendix D). After receiving official permission (see Appendix E), the researcher asked for and received complete class lists from the three instructors. Using the class lists, the eight scenarios were randomly assigned to the Japanese subjects.

The questionnaires translated into Japanese were sent by the researcher directly to the three instructors in Japan, and were distributed by them to all students in their classrooms. The instructors agreed to provided approximately 30 minutes at the beginning of their class period for students to complete the questionnaire items. All students were given a cover letter explaining the study (see Appendix F) and requested to read and sign the informed consent (see Appendix G). If they completed the informed 
consent, they were asked to complete the biographical sheet (see Appendix $H$ ) and the questionnaire (see Appendix A \& B), and then return all completed forms to the instructors. All questionnaires were returned by mail to the researcher in the United States. The data were collected from June to July in 1991 
CHAPTER IV

RESULTS

This chapter presents the findings of the data analyses. The chapter begins with a discussion of the sample characteristics and reliability of the scales. Then, the results of the data analyses are reported. Alpha level for all statistical tests was set at .05 in this study.

\section{SAMPLE CHARACTERISTICS}

In this study, the questionnaire was constructed based on the assumption that the subjects were unemployed college students, from 18 to 24 years old, who had had intercultural experiences in U.S. or other Western cultures for no more than three months. In the scenarios, the ingroup discloser was characterized as a student of the same school and about the same age as the subjects, and the outgroup discloser was characterized as an employed individual in his/her thirties (see pp. 46-47). However, of the 328 subjects who completed the questionnaire, 17 subjects were over the age of 24 , and might have been employed. The employed individual in the scenarios, although intended to be perceived an outgroup member in the study, might be identified as an ingroup member by those subjects who were employed and were close to 
the discloser's age.

In addition, few subjects reported a face-to-face interaction with Westerners on daily basis. The Japanese subjects interacted with instructors from Western cultures in the classroom setting, and actual interaction length per person would likely be very limited. However, 13 subjects, including five who were older than 24 years old, reported that they had stayed in Western cultures for a total of more than three months. Thus, a total of 25 subjects did not fully conform to the assumptions regarding age, employment, intercultural experiences.

These 25 non-conforming subjects were compared to the 303 subjects who conformed to all assumptions. The two subsamples were separately analyzed using a two-way analysis of variance (ANOVA) to test the effects of the level of selfdisclosure and group identification. Because there were no significant differences between the non-conforming and conforming subsamples, all subjects were included in the analysis reports herein for a total of 328 subjects, including 75 male and 253 female subjects.

\section{RELIABILITY OF MEASUREMENT}

Cronbach's (1951) alpha statistic was computed for the internal reliability of the scale used in this study. The reliability of the 10 items from McCroskey and McCain's (1974) original social attraction scale is alpha $=.86$. The 
reliability of the 10 items of the Sugita's social attraction scale is alpha $=.89$. The two scales are highly correlated at $\underline{r}=.78(\underline{p}<.001)$. This correlation is shown enough to justify combining the 20 items into a single scale, $\underline{\text { alpha }}=.93$.

\section{DATA ANALYSIS}

Hypothesis 1

Hypothesized differences in perceived social attraction was tested by $\underline{t}$ tests.

H1: For the ingroup members, the high discloser will be perceived to be more socially attractive than the low discloser.

This hypothesis was not supported. In the ingroup condition, perceived social attraction was significantly higher for the low discloser $[\underline{t}(161,165)=-10.4, \underline{p}<.001]$. This result reverses the relationship of the high and low disclosers of the ingroup stated in Hypothesis 1.

\section{Hypothesis 2}

H2: For the outgroup members, the low discloser will be perceived to be more socially attractive than the high discloser.

This hypothesis was supported. In the outgroup condition, perceived social attraction was significantly higher for the low discloser than for the high discloser $[\underline{t}(157,162)=-4.5, \underline{p}<.001]$, which is consistent with Hypothesis 2 . 


\section{Interaction}

Hypothesis 1 and 2 , respectively, compared perceived social attraction for the high and low disclosers in the ingroup or outgroup condition. The interaction between the discloser's level of self-disclosure and the discloser's group identification was tested by a two-way (Level of Selfdisclosure $x$ Group Identification) ANOVA. Figure 4 displays the mean scores of perceived social attraction for four conditions of the discloser and the number of subjects.

\section{Group Identification}

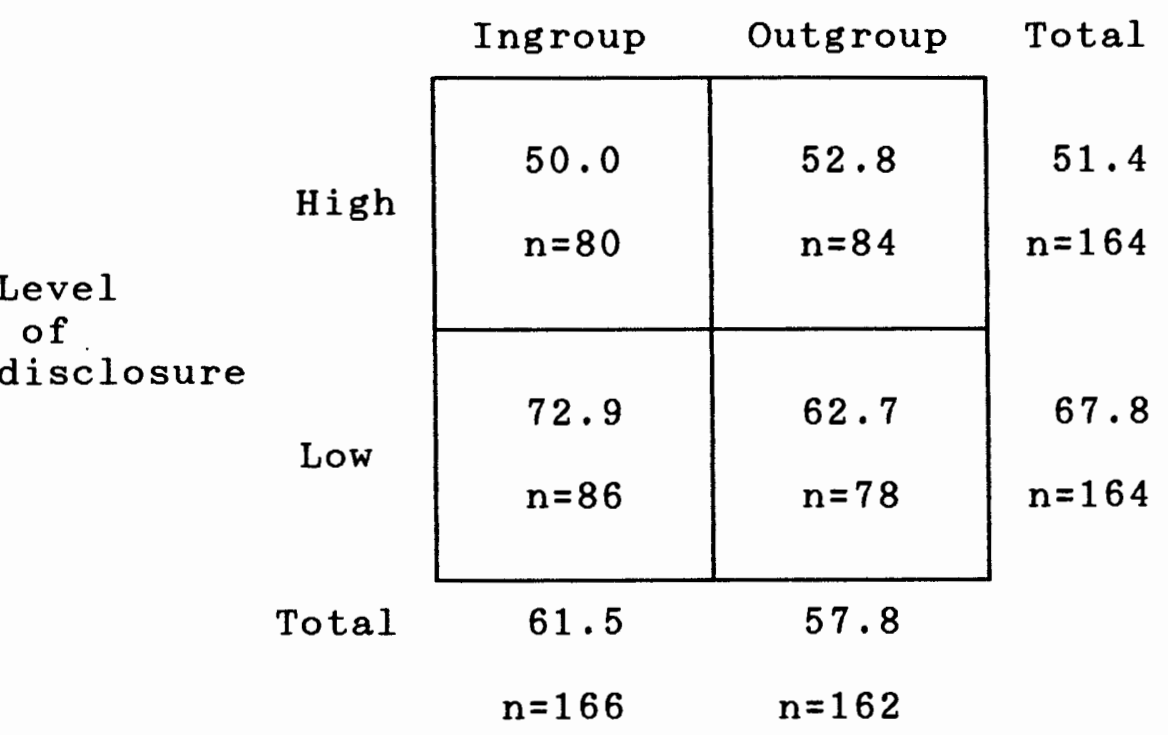

Figure 4. Mean scores of perceived social attraction for four conditions of the discloser and the number of subjects.

Table I presents the results of the two-way ANOVA. 
TABLE I

RESULTS OF THE TWO-WAY ANALYSIS OF VARIANCE

\begin{tabular}{l|cc}
\hline Source & Degree of Freedom & F-value \\
\hline Level of Self-disclosure & 1 & $108.9 * * *$ \\
Group Identification & 1 & $7.5 * *$ \\
Level of Self-disclosure & 1 & $15.2 * * *$ \\
Xroup Identification & & \\
Note: *** p<.001 & & \\
$* *$ p $<.01$ &
\end{tabular}

As shown in Table $I$, the two-way ANOVA revealed that there was a significant interaction between the discloser's level of self-disclosure and the discloser's group identification $[\underline{F}(1,328)=15.2, \underline{p}<.001]$.

Figure 5 graphically displays the mean scores of perceived social attraction by the discloser's level of self-disclosure and the discloser's group identification. In Figure 5, the interaction was graphically shown, with the effect on group identification by the level of selfdisclosure particularly affects perceived social attraction for the ingroup condition. 
Mean Scores of

Perceived Social Attraction

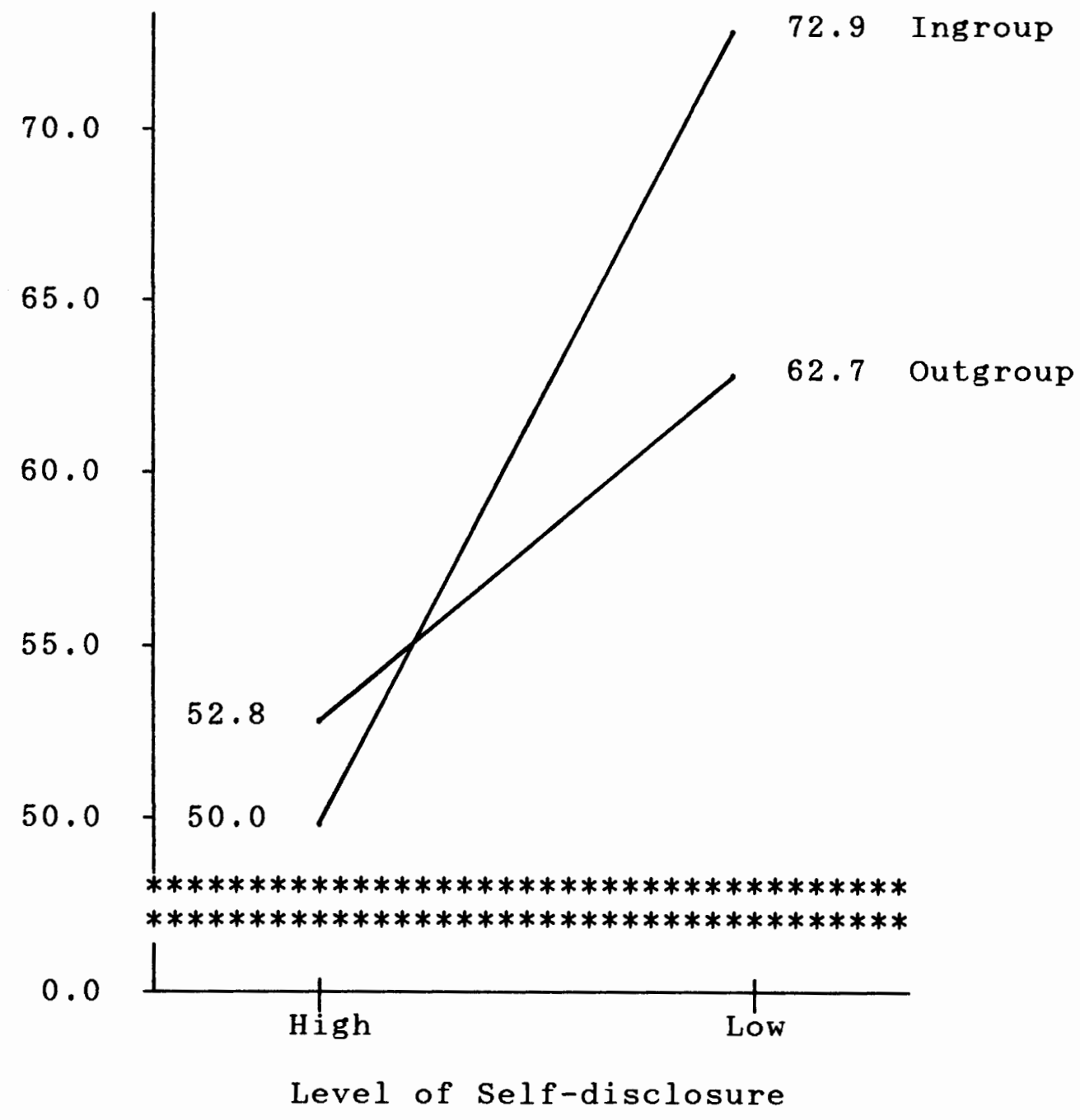

Figure 5. Mean scores of perceived social attraction by the discloser's level of selfdisclosure and group identification.

Within the high self-disclosure condition, no significant differences are observed in perceived social attraction between the ingroup and outgroup disclosers. Within the low self-disclosure condition, perceived social attraction is significantly higher for the ingroup discloser 
than for the outgroup discloser $[\underline{t}(161,164)=5.1, \mathrm{p}<.001]$. Group identification differences appear only when selfdisclosure is low, and high self-disclosure results in low perceived social attraction regardless of the discloser's group identification.

\section{Gender}

To test the possible gender effects, the data were analyzed by using three, three-way ANOVAs. First, the effects of the discloser's gender on the interaction of the discloser's level of self-discloser and group identification was tested by a three-way ANOVA: Level of Self-disclosure $x$ Group Identification x Discloser's Gender. Second, the effects of the subjects' gender was tested by a three-way ANOVA: Level of Self-disclosure $x$ Group Identification $x$ Subjects' Gender. Finally, the effects of gender differences between the disclosure and the subjects was tested by a three-way ANOVA: Level of Self-disclosure $x$ Group Identification $x$ Gender Differences. Each three-way ANOVA respectively revealed no significant effects due to gender. 


\section{CHAPTER V}

\section{DISCUSSION AND CONCLUSION}

The purpose of this study was to extend the study of self-disclosure to Japanese culture, and, using the concept of ingroup and outgroup relationships, examine the relationship between the level of verbal self-disclosure and perceived social attraction in initial interaction between Japanese strangers. Based on the literature on selfdisclosure as well as relevant features of Japanese culture and communication, two hypotheses were constructed and tested by using a Japanese sample living in Japan. T tests and a two-way analysis of variance (ANOVA) were used to test the hypotheses and interaction between the level of selfdisclosure and group identification. In addition, to test for possible gender effects, the data were analyzed by using three, three-way ANOVAs. This chapter discusses the findings of data analyses, study limitations and strengths, and recommendation for future research.

\section{DISCUSSION}

In each scenario used in this study, Japanese subjects took the hypothetical role of the listener in a conversation with a stranger. The subjects gave yes or no answers or 
short responses to the stranger with whom they hypothetically interacted.

In the scenarios, the stranger's self-disclosure level, that is, high or low, was presented by both verbal frequency and topic intimacy of self-disclosure. The low disclosing stranger's utterances were limited to questions about the listener's (i.e., the study subjects') background and each utterance was short. In addition to seeking information about the listener's background, the high disclosing stranger talked about his/her own educational background and the relationship with his/her spouse or girl/boyfriend. The high disclosing stranger received no reciprocal utterances from the listener in terms of verbal frequency and topic intimacy.

The stranger's group identification in each scenario was determined by the stranger's age and social status or role. Since the subjects in this study were college students, the stranger identified as an ingroup member was characterized as a student of the same school and the same age as the subjects. The stranger identified as an outgroup member was characterized as an employed individual in his/her thirties (see Appendix A). 


\section{Hypotheses}

The results of the data analysis in this study did not support Hypothesis 1 which stated that, for the ingroup members, the high discloser would be perceived to be more socially attractive than the low discloser. The results revealed that when a stranger was identified as being an ingroup member, the Japanese subjects perceived a low disclosing stranger to be more socially attractive than a high disclosing stranger. On the other hand, the results of the data analysis supported Hypothesis 2 which stated that, for the outgroup members, the low discloser would be perceived to be more socially attractive than the high discloser. The results revealed that when a stranger was identified as an outgroup member, the Japanese subjects perceived a low disclosing stranger to be more socially attractive than a high disclosing stranger. The results of testing both hypotheses indicate that, for both the ingroup and outgroup members, the low discloser is perceived to be more socially attractive than the high discloser.

Regardless of the strange's group membership, low selfdisclosure led to the positive evaluation of the stranger's perceived social attraction and high self-disclosure led to the negative evaluation of the stranger's perceived social attraction. The results of testing the two hypotheses suggest that in initial interaction between Japanese strangers, the level of self-disclosure represented by 
verbal frequency and topic intimacy, not the stranger's membership, directly influenced evaluation of the stranger's perceived social attraction. In other words, the intervening variable, ingroup and outgroup relationships, did not affect the causal relationship between the independent variable, the level of self-disclosure, and the dependent variable, that is, perceived social attraction. In a stranger-to-stranger encounter, the level of selfdisclosure was a main factor in determining the stranger's perceived social attraction, and low self-disclosure is perceived to be the appropriate level of self-disclosure, while high self-disclosure is considered to be inappropriate.

In this study, the level of self-disclosure consisted of both verbal frequency and topic intimacy. With regard to topic intimacy of self-disclosure, the results of this study are consistent with Nakanishi's (1986) study, which found that, in initial interaction between Japanese strangers, "the high discloser was perceived to be significantly less socially attractive than the low or moderate self-discloser" (p. 185). However, the results of this study contrast somewhat with U.S. studies (Chaikin \& Derlega, 1974; Cozby, 1972; Davis \& Sloan, 1974; Giannandrea \& Murphy, 1973; Mann \& Murphy, 1975; Lange \& Grove, 1981) which conclude that Americans perceive the low discloser as well as the high discloser to be less socially attractive, while the moderate 
discloser was perceived to be the most socially attractive. The present study and Nakanishi's research suggest that Japanese perceive the low discloser to be more attractive than did American participants in comparable studies conducted in the Unites States. These results reflect a difference between two cultures in perception of appropriate self-disclosure in initial interaction between strangers.

More specifically, Barnlund (1975) compared the preferred conversation topics between Japanese and Americans. He found that in interaction with a stranger, both Japanese and Americans do not encourage verbal intimacy with strangers. However, he also found that the conversation topics of Japanese are limited to such low intimate ones as matters of interest and taste and opinions of public issues, while Americans talk about topics considered to be more intimate including work or studies and financial matters.

Further, Barnlund (1975) compared the level of selfdisclosure on each conversation topic between Japanese and Americans. The results revealed that overall Japanese disclose much less than Americans. More precisely, The average score of self-disclosure level for Americans was almost 1.5 times that for Japanese (see p. 30). Americans' average score of self-disclosure level on the least preferred topics was equal to or higher than those of Japanese on all topics but the most preferred topics. 
Thus, compared with Americans, the range of selfdisclosure topics chosen by Japanese is more limited, and further the level of self-disclosure on conversation topics in Japanese communication is much lower. In addition, Gudykunst and Nishida (1984) report that, in an interaction with a stranger, Japanese engage in lower levels of selfdisclosure than do Americans. Because of these differences in the level of self-disclosure, Japanese, unlike Americans, may perceive low self-disclosure to be more appropriate, rather than inappropriate.

With regard to verbal frequency, the results of this study seem to reflect Japanese culture which negatively evaluates talkativeness or verbosity in communication. As Barnlund (1975) notes, in Japanese culture, "articulate persons, especially talkative ones, are seen as foolish or even dangerous" (p. 89). Especially in initial interaction between strangers in which interactants do not have enough information about the other to judge the other's social attractiveness, the notion "speaking is a negative act" (Bruneau \& Ishii, 1988, p. 310) might be more strongly acknowledged as a communication norm by the Japanese subjects, and influence their perception of the stranger. Communication in high context cultures is regulated by the situational context (Hall, 1974). In Japanese culture, communication competence is related to the ability to adapt to the situation and behave appropriately to the situational 
demands, to accurately to discern the relationship level of communication from its context, and to understand and interpret the implicit expression from the situational context (Iritani, 1971; Nakanishi, 1986; Okabe, 1983). The results of this study indicate that, in conversation with a stranger, choosing low intimate topics, such as asking the other's social background, and talking less would more likely be perceived by Japanese to be situationally appropriate. On the other hand, disclosing about high intimate topics such as the relationship with one's spouse or girl/boyfriend seems to be considered a inappropriate behavior in the situational context.

The results of this study are consistent with Altman and Taylor's (1973) social penetration theory which proposes that, in an early stage of relationship, limited variety of non-intimate topics are exchanged. According to Miller and Steinberg's (1975) concept of three kinds of information, the information disclosed and sought in the interaction with a stranger can be categorized into cultural information. Among Japanese, asking social background information is a "ritual" form perceived to be an appropriate behavior in a stranger-to-stranger interaction. However, seeking background information is also important, in that, such information influences the speaker's use of appropriate communication style (Barnlund, 1989; Condon, 1977; Yoneyama, 1979). This latter function is consistent with Grove's 
(1991) observation about one of the functions of information disclosed to the other. Thus, social penetration theory appears useful in the study in Japanese cultural context. Berger and Calabrese's (1975) uncertainty reduction theory posits that, in a stranger-to-stranger interaction, uncertainty about other's behavior is relatively high. In that situation, exchanged verbal communication is low and interactants engage in information seeking behavior to reduce uncertainty. However, in the scenarios, selfdisclosure by the stranger was not reciprocated by the subjects taking the hypothetical role of the listener. The subjects did not use any verbal means to reduce their uncertainty or increase attributional confidence in the conversation in the scenarios. Therefore, the results of the study did not test this important feature of uncertainty reduction theory.

The results of testing the two hypotheses imply that in initial interaction between Japanese strangers, the low level of self-disclosure in terms of verbal frequency and topic intimacy is related to a concept of appropriate selfdisclosure, and leads to high perceived social attraction. The high level of self-disclosure is considered to be inappropriate in the context, and leads to low perceived social attraction. In a stranger-to-stranger encounter in Japanese culture, the stranger's perceived social attraction is regulated by norms for appropriate self-disclosure which, 
based on the findings of this study and others (Barnlund, 1975, 1989; Nakanishi, 1986), calls for lower selfdisclosure levels than in comparable U.S. contexts.

\section{Interaction}

The initial results of hypothesis testing suggest that the stranger's level of self-disclosure is a main factor in determining the stranger's perceived social attraction, and regardless of the stranger's group membership, low disclosing stranger is perceived to be more socially attractive than high disclosing stranger. However, the results of the two-way ANOVA revealed that there was a significant interaction between the stranger's level of self-disclosure and the stranger's group identification, and that ingroup membership led to greater perceived social attraction than outgroup membership.

Further, by using t tests, mean score differences of perceived social attraction by the stranger's group identification were compared for both the high and low selfdisclosure levels. The results revealed that for high selfdisclosure, the Japanese subjects did not distinguish ingroup and outgroup members, and perceived both of them negatively. On the other hand, for low self-disclosure, the Japanese subjects clearly distinguished ingroup and outgroup members, and perceived a stranger identified as being an ingroup member to be more socially attractive than a 
stranger identified as an outgroup member.

The results of the two-way ANOVA and subsequent $t$ tests suggest that the Japanese subjects applied communication norms for the appropriate self-disclosure differently to the low disclosing strangers identified to be ingroup and outgroup members, while they applied the norms in the same way to the high disclosing strangers. As a result, the highest perceived social attraction was produced by a low disclosing stranger identified as an ingroup member.

The results, which indicate a difference in application of the norms by the stranger's membership, support selected characteristics of collectivistic cultures as defined by Triandis (1986) and others (Gudykunst, Yoon, \& Nishida, 1987), in that, members of collectivistic cultures distinguish ingroups and outgroups and apply different value standards to each of them. Also the results point to several specific expectations for ingroup members based on the Japanese concept of group harmony and norms associated with group harmony.

Japanese culture, which is characterized by "groupness," emphasize interdependence based on harmony among group members. "Harmony, ..., is achieved by determining what behavior is socially appropriate in the context" (Gudykunst \& Nishida, 1984, p. 27). In communication among ingroup members, the assertive or direct 
expression of one's opinion of feelings as well as the expression of one's individual identity is not welcome by other group members (Nakane, 1974; Okabe, 1983), because it may dissolve the relationship based on the equality of group members.

In Japanese culture, too much self-expressiveness of assertiveness if often discouraged because of its possible negative effects in harmonious relationships among members of a group (Nakanishi, $1986, \mathrm{p} .185$ ).

As reflected in the Japanese old saying "deru kugiwa utareru" ("the nail that sticks out gets banged down"), Japanese ingroup relationships tend to restrain each individual's identity and emphasize conformation with other group members (Ada, 1972; Araki, 1973; Cathcart \& Cathcart, 1988; Okabe, 1983; Reischaure, 1988). In communication within a group, Japanese avoid directly expressing their inner feelings or opinions for fear that their feelings or opinions may be different from or counter to those of others and violate the harmonious relationships with others. Okabe contends:

The Japanese, therefore, display great cautiousness in expressing personal opinions and in modifying their opinions to be consistent with those of others around them (p. 26).

According to Mizutani (1979), the communication norms of group harmony are already taught in the classrooms at elementary school, and a talkative person has difficulty being accepted as a group member by other Japanese. 
In this cultural frame, even in a stranger-to-stranger interaction, if the stranger is identified as an ingroup member, Japanese may apply communication norms based on group harmony, and hold higher expectations that the stranger will not be self-assertive or too talkative, but appropriately engage in low self-disclosure. In other words, the behavior of ingroup members seems to be more restricted by the communication norms for the appropriate self-disclosure, in part because of the norms for maintaining group harmony. If a stranger identified as being an ingroup member meets this expectation, Japanese may perceive the stranger to be "an ideal group member" and perceive greater social attraction. However, if the stranger violates the group norms and enacts behavior considered self-assertive or talkative, that is, high selfdisclosure, Japanese may perceive the stranger negatively. As discussed in the literature review, while being more sensitive to communication behavior of a stranger identified as an ingroup member, Japanese may tend to be indifferent to the behavior of a stranger identified as an outgroup member because outgroup members do not directly influence the harmonious relationships among ingroup members. So even if a stranger follows the norms, unless they identify the stranger as belonging to the ingroup, Japanese do not perceive the stranger as being as socially attractive as ingroup members. 
In short, in this study, the stranger's group identification was found to mediate the relationship between the stranger's level of self-disclosure and the stranger's perceived social attraction. If the stranger's level of self-disclosure is a main factor in determining the strange's perceived social attrition and low self-disclosure leads to positive perceived social attraction, the stranger's "ingroup" membership produces greater perceived social attraction than the stranger's "outgroup" membership. At the high self-disclosure level, there were no differences in perceive social attraction for ingroup and outgroup members. This result raises questions about the concept of ingroup and outgroup relationships in collectivistic cultures as defined by Triandis (1986). The findings imply that Japanese do not distinguish ingroup and outgroup members under one particular condition. No apparent differences in perceived social attraction between ingroup and outgroup members for high self-disclosure emphasizes the importance of the norms for the appropriate self-disclosure more than the stranger's group membership in a stranger-to-stranger interaction in Japanese culture.

\section{Gender}

In this study, no significant gender effects on perceived social attraction were found. Previous U.S and some Japanese studies found gender differences in relation 
to self-disclosure. For example, Jourard's (1971) research revealed that American females disclose more than do American males. Rosenfeld, Civiskly, and Herron (cited in Adler, Lawrence, \& Towne, 1986) found that American males are more willing to disclose about less intimate or personal topics to a stranger.

According to Nakanishi's (1986) study of selfdisclosure with native Japanese speakers, Japanese females prefer low self-disclosure to high self-disclosure more than do Japanese males. In addition, in his research with Japanese business people, Ishikawa (cited in Ishii \& Bruneau, 1988) found that Japanese businesswomen would like to choose a quiet male for a husband. These studies suggest that the subjects' and the discloser's gender affect the discloser's perceived social attraction. However, the results of this study indicate that, in initial interaction between Japanese strangers, gender does not influence the relationship between the level of self-disclosure and perceived social attraction.

\section{SUMMARY OF FINDINGS}

In initial interaction between strangers, interactants usually do not have much information about others. In this study, in the interaction with a stranger constructed as taking place at a bus stop, the Japanese subjects seemed to primarily depend on whether the stranger followed the norms 
associated with the appropriate level of self-disclosure, and evaluated the stranger's social attractiveness on this basis. Low self-disclosure, normatively appropriate in such a context, received positive evaluation, while high selfdisclosure, considered to be norm violating behavior, led to negative evaluation of the stranger's perceived social attraction.

Further, for the stranger who followed the norms of the appropriate level of self-disclosure, the stranger's group identification was found to regulate the degree to which the level of self-disclosure affected perceived social attraction. As a mediator in the relationship between the level of self-disclosure and perceived social attraction, ingroup membership led to more perceived social attraction than the outgroup membership. Thus, when the stranger was identified as an ingroup member followed the norms, the most positive social attraction was produced. In this study, no effects due to gender were found.

\section{STUDY LIMITATIONS AND STRENGTHS}

First, drawing on the literature on self-disclosure and using the concept of ingroup and outgroup relationships, this study examined the relationship between the level of self-disclosure and perceived social attraction in initial interaction between Japanese strangers. Because of this purpose, some other concepts related to self-disclosure and 
interpersonal attraction, e.g., reciprocity, trust, and liking, were not directly examined in this study.

Second, in this study, the level of verbal self-

disclosure consisted of two variables: verbal frequency and topic intimacy. Although the study results revealed that the level of self-disclosure was the main factor in determining the stranger's perceived social attraction, due to the confounded effects of the two variable, this study did not clarify which variable had more significant effect in perceived social attraction in initial interaction between Japanese strangers.

Third, because of operational difficulties (see p. 5), the nonverbal component of self-disclosure was not addressed in the study. However, in Japanese culture, nonverbal cues have great value in communication as Japanese tend to depend more on nonverbal and situational cues to interpret the messages rather than verbal cues in interpersonal communication (Hall, 1976; Kindaichi, 1975).

Fourth, because this study formulated hypotheses based on the concept of self-disclosure as developed in the United States, findings might reflect self-disclosure as a communication act in the stranger-to-stranger interaction, but might not necessarily reflect the Japanese concept itself. The same thing can be said about the scenarios which were used to describe the intimacy level of selfdisclosure topics in the questionnaire. Since no criteria 
were found in the literature that sharply distinguished self-disclosure topics by level, topics for high and low self-disclosure in the scenarios were selected based on U.S. studies and Barnlund's (1975) general suggestions as to appropriate self-disclosure topics in Japanese communication. The problem remains as to whether the Japanese subjects perceived the level of self-disclosure topics in the scenarios as the researcher had intended. Finally, as an operational limitation, the conversation between strangers in the scenarios used in this research were relatively artificial, not natural. In general, Japanese are indifferent to strangers and rarely interact with strangers (Barnlund, 1989; Nakane, 1974; Yoneyama, 1976). Since this study constructed the hypothetical communication situation and conversation between strangers, it is not certain whether the findings of the study can be generalized to naturally occurring interaction between Japanese strangers.

There are strengths as well as limitations of this study. First, the study of self-disclosure has been done mainly in the United States, and only a few studies have directly examined self-disclosure in Japanese culture. In such a circumstance, focusing on verbal self-disclosure, the present study extended the study of self-disclosure to the Japanese cultural context and provided more accurate information about the relationship between the level of 
self-disclosure and perceive social attraction in relation to the concepts of ingroup and outgroup relationships.

Second, as an intracultural study, this study used an adequate size of sample consisting of native Japanese speakers living in Japan. Intercultural and cross-cultural studies tend to rely on Japanese samples living in the United States. However, this study provided more culturespecific empirical data adding to available information on Japanese communication styles.

Third, in this study, the data was collected by using an instrument with high reliability (alpha $=.93)$. In addition to McCroskey and McCain's (1974) social attraction scale $(\underline{a l p h a}=.86)$, a culture-specific scale of perceived social attraction ( $\underline{a l p h a}=.89$ ) was constructed by the researcher and employed to assess perceived social attraction of the Japanese subjects.

\section{FUTURE RESEARCH}

The findings of this study and foregoing limitations suggest directions of future research. First, the separate analysis of the two variables, verbal frequency and topic intimacy is necessary to supplement this study, and provide more accurate information about the relationship between the level of verbal self-disclosure and perceived social attraction in Japanese communication.

Second, due to the operational difficulties, this study 
did not test the nonverbal component of self-disclosure. However, the research on nonverbal self-disclosure in Japanese culture may reveal different values of nonverbal self-disclosure from that of the United States as well as Japanese communication style emphasizing nonverbal communication.

Third, due to the lack of criteria of self-disclosure in Japanese culture, both the study hypotheses and the instrument used in this study were constructed in large part based on the U.S. concept of self-disclosure. Therefore, the research findings might not reflect actual Japanese self-disclosive communication. To develop intracultural studies of communication in the Japanese cultural context, it is necessary to explore the concept and specific criteria of self-disclosure in Japanese culture.

Fourth, it was found in this study that Japanese subjects distinguished ingroup and outgroup members for low self-disclosure, but not for high self-disclosure. The latter finding is not consistent with the definition of collectivistic cultures by Triandis (1986), in that members of collectivistic cultures draw sharper distinction between ingroup and outgroups. The finding of the present study imply that Japanese distinguish ingroups and outgroups under a certain condition, but do not distinguish under another condition. Future study of the concept of ingroup and outgroup relationships in Japanese communication needs to 
consider this point.

Fifth, the results of the data analyses in this study revealed no significant gender effects. Drawing on previous U.S. and Japanese studies and relevant features of Japanese society, it was expected that gender would affect the relationship between the level of self-disclosure and perceived social attraction. However, in this study, any conclusive reasons for this unexpected finding were found. To clarify this study finding, further research is anticipated.

Finally, as noted in the literature review, selfdisclosure is viewed as an important concept both in uncertainty reduction theory and social penetration theory. This study was not designed as a direct test of either theory. However, several points warrant comments on both theories.

Uncertainty reduction theory does not distinguish between stranger types. However, the results of this study and Mizutani's (1979) research seem to indicate that stranger types are distinguishable in terms of ingroup and outgroup membership, and that self-disclosure behavior is differently evaluated based on this distinction. Further applications of uncertainty reduction theory to high context, collectivistic cultures such as Japan where ingroup and outgroup distinctions are important, even in a strangerto-stranger encounter, need to take into account this 
subtle, but important feature.

The results of this study suggest that social penetration theory can be applied to communication in the Japanese cultural context. However, as Barnlund (1975, 1989) discussed, the level of self-disclosure on topics for Japanese is lower than for Americans. The differences between Japanese and Americans in the level of selfdisclosure imply that, although information about the stranger's background can be categorized into cultural information, it does not necessarily fit the western definition in terms of the topic intimacy level. Future applications of social penetration theory may need to be more sensitive to what constitutes cultural information in Japanese cultural context.

\section{CONCLUSION}

This study extended the study of self-disclosure to the Japanese cultural context using a Japanese sample living in Japan. It provided information about verbal self-disclosure as a communication act in initial interaction between Japanese strangers in relation to the concepts of perceived social attraction and ingroup and outgroup relationships. The findings of the study suggested that, in a Japanese stranger-to-stranger encounter, self-disclosure produced either positive or negative social attraction according to the discloser's self-disclosure level and group membership. 
In initial interaction between Japanese strangers, low selfdiscloser led to higher perceived social attraction, and the stranger's ingroup membership led to greater perceived social attraction. By providing data collected in Japan, this study suggests culture-specific Japanese verbal communication styles in a specific communication context, and illuminates particular functions of the concept of ingroup and outgroup relationships in initial interaction between strangers in modern Japanese society. 
REFERENCES

Adler, R. B., Rosenfeld, B. R., \& Towne, N. (1986). Interplay ( $3 \mathrm{rd}$ ed). New York, NY: Hold, Rinehart and Winston.

Aida, Y. (1972). Nihon no ishiki kohzo [The structure of the Japanese consciousness]. Tokyo, Japan: Kodansha.

Araki, H. (1973). Nihonjin no kodo-yoshiki [Japanese Communication style]. Tokyo, Japan: Kodansha.

Altman, I., \& Taylor, D. (1973). Social Penetration. New York, NY: Holt, Rinehart, and Winston.

Altman, I., Vinsel, A., \& Brown, B. (1981). Dialectical conceptions in social psychology: An application to social penetration and privacy regulation. In L. Berkowitz (Ed.), Advances in experimental social psychology (pp. 107-160). New York, NY: Academic Press.

Barnlund, D. C. (1975). Public and private self in Japan and the United States: Communicative styles of two cultures. Tokyo, Japan: Simul Press.

Barnlund, D. C. (1979). Verbal self-disclosure: Topics, targets, depth. In E. C. Smith \& L. F. Luce (Eds.), Toward internationalism: Readings in cross-cultural communication (pp. 83-101). Rowley, MA: Newbury House.

Barnlund, D. C. (1989). Communicative styles of Japanese and Americans: Images and realities. Belmont, CA: Wadsworth Publishing Company.

Baxter, L. A. (1979). Self-disclosure as a relationship disengagement strategy: An explorately investigation. Human Communication Research, 10, 215-222.

Berg, J. H., \& Archer, R. L. (1983). The disclosure-liking relationship: Effects of self-perception, order of disclosure, and topical similarity. Human Communication Research, 10, 269-281.

Berger, C. R. (1975). Proactive and retroactive attribution processes in interpersonal communication. Human Communication Research, $2,33-50$. 
Berger, C. R. (1979). Beyond initial interaction:

Uncertainty, understanding, and the development of

interpersonal relationships. In $H$. Glides \& $R$. St.

Clair (Eds.), Language and social psychology (pp. 122-

143). Oxford: Basil Blackwell.

Berger, C. R. (1986). Uncertainty outcome values in predicted relationships: Uncertainty reduction theory

then and now. Human communication Research, 13, 34-38.

Berger, C. R. (1987). Communicating under uncertainty. In M. E. Roloff \& G. R. Miller (Eds.), Interpersonal processes: New directions in communication research (pp. 39-62). Newbury Park, CA: Sage Publications.

Berger, C. R., \& Calabrese, R. J. (1975). Some exploration in initial interaction and beyond: Toward a developmental theory of interpersonal communication. Human Communication Research, 1, 99-112.

Berger, C. R., Gardner, R. R., Parks, M. R., Schulman, L., \& Miller, G. R. (1976). Interpersonal epistemology and interpersonal communication. In G. R. Miller (Ed.), Explorations in interpersonal communication (pp. 149171). Beverly Hills, CA: Sage Publications.

Bochner, A. P. (1982). On the efficacy of openness in close relationships. In M. Burgoon (Ed.), Communication yearbook 5 (pp. 109-124). Newbury Park, CA: Sage Publications.

Bradac, J. J., Tardy, C. H., \& Hosman, L. A. (1980). Disclosure styles and a hint at their genesis. Human Communication Research, $\underline{6}, 228-238$.

Cathcart, D., \& Cathcart, R. (1988). Japanese social experience and concept of groups. In L. A. Samovar \& $R$. E. Porter (Eds.), Intercultural communication: A reader (pp. 186-192). Belmont, CA: Wadsworth Publishing Company.

Chaikin, A. L., \& Derlega, V. J. (1974). Self-disclosing. Morristown, NJ: General Learning Press.

Cline, R. J. (1983). The acquaintance process as relational communication. In R. N. Bostrom \& B. H. Westley (Eds.), Communication yearbook 7 (pp. 396-413). Newbury Park, CA: Sage Publications.

Cline, R. J., \& Muslof, K. E. (1985). Disclosure as social exchange: Anticipated length of relationship, sex roles, and disclosure intimacy. Western Journal of Speech Communication, 49, 43-56. 
Condon, C. J. (1977). Interpersonal communication. New York, NY: Macmillan Publishing co.

Cozby, P. C. (1972). Self-disclosure, reciprocity, and liking. Sociometry, $\underline{35}, 151-160$.

Cronbach, L. J. (1951). Coefficient alpha and the internal structure of tests. Psychometrika, 16, 279-334.

Davis, J. D., \& Sloan, M. L. (1974). The basis of interviewee matching of interviewer self-disclosure. British Journal of Social and Clinical psychology, 13 , 359-367.

Derlega, V. J., \& Chaikin, A. L. (1988). Privacy and self disclosure in social relationships. Journal of Social Issues, $\underline{33}, 102-115$.

Derlega, V. J., Wilson, M., \& Chaikin, A. L. (1976). Friendship and disclosure reciprocity. Journal of Personality and Social Psychology, 34, 578-582.

DeVito, J. A. (1983). The interpersonal communication book (3rd ed.). New York, NY: Harper \& Row.

Dindia, K. (1988). A comparison of several statistical tests of reciprocity of self-disclosure. Communication Research, 15, 726-752.

Douglas, W. (1991). Uncertainty, information-seeking, and liking during initial interaction. Western Journal of Speech Communication, 54, 66-81.

Eakins, B. W., \& Eakins, R. G. (1978). Sex differences in human communication. Boston, MA; Houghton Mifflin.

Giannandrea, V., Murphy, K. C. (1973). Similarity of selfdisclosure and return for a second interview. Journal of Counceling Psychology, 20, 545-548.

Gilbert, S. J., \& Hornstein, D. (1975). The communication of self-disclosure: Level versus valence. Human Communication Research, 1, 316-322.

Glaser, B. G., \& Strauss, A. L. (1967). The discovery of grounded theory: Strategies for qualitative research. New York, NY: Aldine Gruyter.

Grove, T. G. (1991). Dyadic interaction: Choice and change in conversations and relationships. Dubuque, IA: Wm. C. Brown Publishers. 
Gudykunst, W. B. (1983). Uncertainty reduction and predictability of behavior in low-and high-context cultures: An explorately study. Communication Quarterly, $\underline{31}, 49-55$.

Gudykunst, W. B. (1985). The influence of cultural similarity, type of relationship, and self-monitoring on uncertainty reduction processes. Communication Monograph, 52, 203-217.

Gudykunst, W. B. (1989). Culture and the development of interpersonal relationships. In J. A. Anderson (Ed.), Communication yearbook 12 (pp. 315-354). Newbury Park, CA: Sage Publications.

Gudykunst, W. B., Chua, E., \& Gray, A. J. (1987). Cultural dissimilarities and uncertainty reduction processes. In M. L. McLaughlin (Ed.), Communication yearbook 10 (pp. 456-469). Newbury Park, CA: Sage Publications.

Gudykunst, W. B., \& Hammer, M. R. (1988). The influence of social identity and intimacy of interethnic relationships on uncertainty reduction process. Human Communication Research, 14, 596-601.

Gudykunst, W. B., \& Nishida, T. (1983). Social penetration in Japanese and American close friendships. In R. N. Bostrom \& B. H. Westley (Eds.), Communication yearbook 7 (pp. 592-609). Newbury Park, CA: Sage Publications.

Gudykunst, W. B., \& Nishida, T. (1984). Individual and cultural influences on uncertainty reduction. Communication Monograph, 51, 23-36.

Gudykunst, W. B., Nishida, T. (1986). Attributional confidence in low- and high-context cultures. Human Communication Research, 12, 525-549.

Gudykunst, W. B., \& Nishida, T. (1987) The influence of cultural variability on perceptions of communication behavior associated with relationship terms. Human Communication Research, 13, 147-166.

Gudykunst, W. B., Nishida, T., Koike, H., \& Shiino, N. (1986). The influence of language on uncertainty reduction: An explorately study of Japanese-Japanese and Japanese-North American interactions. In M. McLaughlin (Ed.), Communication yearbook 9 (pp. 555-575). Beverly Hills, CA: Sage Publications.

Gudykunst, W. B., \& Ting-Toomey, S. (1988). Culture and affective communication. American Behavioral Scientist, $\underline{31}, 384-400$. 
Gudykunst, W. B., Ting-Toomey, S., \& Chua, E. (1988). Culture and interpersonal communication. Newbury Park, CA: Sage Publications.

Gudykunst, W. B., Yang, S-M. , \& Nishida, T. (1985). A crosscultural test of uncertainty reduction theory: comparisons of acquaintances, friends, and dating relationships in Japan, Korea, and the United States. Human Communication Research, 11, 407-454.

Gudykunst, W. B., Yoon, Y-C., \& Nishida, T. (1987). The influence of individualism-collectivism on perceptions of communication ingroup and outgroup relationships. Communication Monographs, 54, 295-306.

Hall, E. T. (1976). Beyond culture. Garden City, NY: Anchor Press.

Hecht, M., Shepherd, T., \& Hall, M. J. (1979). Multivariate indices of the effects of self-disclosure. Western Journal of Speech Communication, 43, 235-245.

Hofstede, G. (1980). Culture consequences. Beverly Hills, CA: Sage.

Hofstede, G., \& Bond, M. H. (1984). Hofstede's culture dimensions: An independent validation using Rokeach's value survey. Journal of Cross-Cultural Psychology, 15, 417-433.

Hosman, L. A., \& Tardy, C. H. (1980). Self-disclosure and reciprocity in short-and long-term relationships: An experimental study of valuational and attributional consequences. Communication Quarterly, 28, 20-30.

Hosman, L. A. (1987). The evaluation consequences of topic reciprocity and self-disclosure reciprocity. Communication Monographs, 54, 420-435.

Hui, C. H., \& Triandis, H. C. (1986). Individualismcollectivism: A study of cross-cultural researchers. Journal of Cross-Cultural Psychology, 17, 225-248.

Iritani, T. (1971). Kotoba to ningen-kankei [Language and interpersonal relationships]. Tokyo, Japan: Kodansha.

Ishida, T. (1984). Conflict and its accommodation: Omote-ura and uchi-soto relations. In E. S. Krauss, T. P. Rohlen, \& P. G. Steinholf (Eds.), Conflict in Japan. Honolulu, HI: University of Hawaii Press. 
Ishii, S., \& Bruneau, T. (1988). Silence and silences in cross-cultural perspective: Japan and the United States. In L. A. Samovar \& R. E. Porter (Eds.), Intercultural communication: A reader (2nd ed.) (pp. 310-315). Belmont, CA: Wadsworth Publishing Company.

Johnson, C, L., \& Johnson, F. A. (1975). Interaction rules and ethnicity: The Japanese and Caucasians in Honolulu. Social Forces, 54, 452-466.

Jorden, E. H., \& Noda, M. (1987). Japanese: The spoken language. New Heaven, NJ: Yale University Press.

Jourard, S. M. (1958). A study of self-disclosure. Scientific American, 198, 77-82.

Jourard, S. M. (1959). Healthy personality and selfdisclosure. Mental Hygiene, 43, 499-507.

Jourard, S. M. (1968). Disclosing man to himself. Princeton, NJ : Van Nostrand.

Jourard, S. M. (1971). The transparent self (2nd ed.). Princeton, NJ: Van Nostrand.

Jourard, S. M. (1971). Self-disclosure: An experimental analysis of the transparent self. New York, NY: John Wiley.

Jourard, S. M., \& Lasakow, P. (1958). Some factors in selfdisclosure. Journal of Abnormal and Social Psychology, 56, 910-998.

Kang, K., \& Pearce, W. B. (1983). Reticence: A transcultural analysis. Communication, $8,79-106$.

Kellermann, K. (1986). Anticipation of future interaction and information exchange in initial interaction. Human Communication Research, 13, 41-75.

Kincaid, D. L. (Ed.). (1987). Communication theory: Eastern and western perspectives. New York, NY: Academic Press.

Kindaichi, H. (1975). Nihonjin no gengo hyogen [Japanese verbal expression]. Tokyo, Japan: Kodansha.

Kitao, K., \& Kitao, K. (1989). Intercultural communication: Between Japan and the United States. Tokyo, Japan: Eishosha-Shinsha. 
Klopf, D., \& Cambra, R. (1979). Communication apprehension among college students in America, Australia, Japan, and Korea. Journal of Psychology, 105, 27-31.

Knapp, M. L. (1984). Interpersonal communication and human relationships. Newton, MA: Allyn and Bacon Inc.

Kunihiro, M. (1976). The Japanese language and intercultural communication. In Japan Center for International Exchange (Ed.), The silent power: Japan's identity and world role. Tokyo, Japan: Simul Press.

Lange, J. I., \& Grove, T. G. (1981). Sociometric and atomic responses to three levels of self-disclosure dyads. Western Journal of Speech Communication, 45, 355-362.

Levinger, G. (1974). A three level approach to attraction: Toward and understanding of pair relatedness. In $T$. L. Huston (Ed.), Foundations of interpersonal attraction. New York, NY: Academic Press.

Littlejohn, S. W. (1989). Theories of human communication (3rd ed.). Belmont, CA: Wadsworth Publishing Company.

Lynn, S. J. (1978). Three theories of self-disclosure exchange. Journal of Experimental Social Psychology, $14,466-479$.

Mann, B., \& Murphy, K. C. (1975). Timing of self-disclosure, reciprocity of self-disclosure, and reactions to initial interview. Journal of Counseling Psychology, 22, 304-398.

Maruyama, M. (1961). Nihon no shiso [The intellectual tradition in Japan]. Tokyo, Japan: Iwanami Shoten.

Miller, G. R., \& Steinberg, M. (1975). Between people: A new analysis of interpersonal communication. Chicago, IL: Science Research associates.

Miller, L. G., Berg, J. H., \& Archer, R. L. (1983). Openers: Individuals who elicit intimate self-disclosure. Journal of Personality and Social Psychology, 44, 12341244 .

Mizutani, O. (1979). Hanashi-kotoba to Nihonjin: Nihongo no seitai [Spoken language and Japanese: A mode of Japanese language]. Tokyo, Japan: Kaitakusha.

Morsbach, H. (1976). Aspects of nonverbal communication in Japan. In L. A. Samovar \& R. E. Porter (Eds.), Intercultural communication: A reader (2nd ed) (pp. 240-259). Belmont, CA: Wadsworth Publishing Company. 
Morton, T. L., Alexander, J. F., \& Altman, I. (1976). Communication and relationship definition. In G. R Miller (Ed.), Explorations in interpersonal communication (pp. 105-125). Beverly Hills: Sage Publications.

McCracken, G. (1988). The long interview. Newbury Park, CA: Sage Publications.

McCroskey, J. \& McCain, T. (1974). The measurement of interpersonal attraction. Speech Monographs, 41 , 261266 .

McLaughlin, M. L. (1979). Relationship of situational preference to self-disclosure and predisposition to communication. Communication Quarterly, 27, 3-11.

Nakane, C. (1970). Japanese society. Berkeley, CA: University of California Press.

Nakane, C. (1974). The social system reflected in interpersonal communication. In J. Condon \& M. Saito (Ed.), Intercultural encounters with Japan (pp. 124131). Tokyo, Japan: Simul Press.

Nakanishi, M. (1986). Perceptions of self-disclosure in initial interaction: A Japanese sample. Human Communication Research, 13, 167-190.

Norton, R. (1982). Style, content, and target components of openness. Communication Research, 9 , 33-65.

Norton, R., \& Montgomery, B. M. (1982). Style, content, and target components of openness. Communication Research, g, 399-431.

Okabe, R. (1983). Cultural assumptions of East and West: Japan and the United States. In W. B. Gudykunst (Ed.), Intercultural communication theory: Current perspectives (pp. 21-44). Beverly Hills, CA: Sage Publications.

Pearce, W. B., Sharp, S. M. (1973) Self-disclosing communication. The Journal of Communication, 23, 409425 .

Powell, J. (1969). Why am I afraid to tell you who I am? Niles, Il: Argus Communications.

Quatirone, G. A., \& Jones, E. E. (1978). Selective selfdisclosure with and without correspondent performance. Journal of Experimental Social Psychology, 14, 511-526. 
Reischauer, E. O. (1988). The Japanese today: Change and continuity. Cambridge, MA: The Belknap Press of Harvard University Press.

Roloff, M. E. (1987). Communication and reciprocity within intimate relationships. In M. E. Roloff \& G. R. Miller (Eds.), Interpersonal processes: New directions in communication research (pp. 11-38). Newbury Park, CA: Sage Publications.

Rosenfeld, L. B. (1979). Self-disclosure avoidance: Why I am afraid to tell you who I am. Communication Monographs, $\underline{46}, 63-74$.

Rossiter, C., \& Pearce, W. B. (1975). Communicating Personally. Indianapolis: Bobbs-Merrill.

Rubin, Z. (1975). Disclosing oneself to a stranger: Reciprocity and its limits. Journal of Experimental Social Psychology, 11, 233-260.

Rubin, Z., \& Shenker, S. S. (1978). Friendship, proximity, and self-disclosure. Journal of Experimental Social Psychology, 11, 233-260.

Smith, M. J. (1988). Contemporary communication research methods. Belmont, CA: Wadsworth Publishing Company.

Steele, F. (1975). The open organization: The Impact of secrecy and disclosure on people and organizations. Reading, MA: Addison-Wesley.

Stewart, E. C. (1971). American cultural patterns: A crosscultural perspective. Pittsburgh, PA: University of Pittsburgh.

Tardy, C. H. (1988). Self-disclosure: Objectives and methods of measurement. In C. H. Tardy (Ed.), A handbook for the study of human communication: Methods and instruments for observing, measuring, and assessing communication processes (pp. 323-346). Norwood, NJ : Ablex.

Tardy, C. H., Hosman, L. A., \& Bradac, J. J. (1981). Disclosing self to friends and family: A reexamination of initial questions. Communication Quarterly, 29, 263268 .

Tardy, C. H., \& Hosman, L. A. (1982). Self-monitoring and self-disclosure flexibility: A research note. Western Journal of Speech Communication, 46, 92-97. 
Taylor, D. (1968). The development of interpersonal relationships: Social penetration processes. Journal of Social Psychology, 75, 79-90.

Ting-Toomey, S. (1989). Identity and interpersonal bonding. In M. K. Asante, W. B. Gudykunst, \& E. Newmark (Eds.), Handbook of international and intercultural communication (pp. 351-373). Newbury Park, CA: Sage Publications.

Triandis, H. C. (1986). Collectivism vs individualism: A reconceptualization of a basic concept in cross cultural psychology. In C. Bagley \& G. Velma (Eds.), Personality, cognition, and values: Cross cultural perspectives of childhood and adolescence. London: MacMillan.

Tsujimura, A. (1987). Some characteristics of the Japanese way of Communicaiton. In D. L. Kincaid (Ed.), Communication theory from eastern and western perspectives (pp. 115-126). New York, NY: Academic Press.

Tucker, R. K., Weaver, II. R. L., Fink, C. B. (1981). Research in speech communication. Englewood Cliffs, NJ: Prentice-Hall, Inc..

Vanlear, C. A. Jr. (1987). The formation of social relationships: A longitudinal study of social penetration. Human Communication Research, 13, 299-322.

Wheeless, L. R. (1976). Self-disclosure and interpersonal solidarity: Measurement, validation, and relationships. Human Communication Research, $\underline{3}, 47-61$.

Wheeless, L. R., \& Grotz, J. (1976). Conceptualization and measurement of reported self-disclosure. Human Communication Research, $\underline{2}$, 338-346.

Wheeless, L. R., \& Grotz, J. (1977). The measurement of trust and its relationship to self-disclosure. Human Communication Research, $\underline{3}, 250-257$.

Whilfson, K. \& Pearce, W. B. (1983). A Cross-cultural comparison of the implications of self-disclosure on conversational logics. Communication Quarterly, $\underline{31}$, 249-255.

Won-Doornink, M. J. (1979). On getting to know you: the association between stage of relationship and reciprocity of self-disclosure. Journal of Experimental Social Psychology, 15, 229-241. 
Won-Doornink, M. J. (1985). Self-disclosure and reciprocity in conversation: A Cross-national study. Social Psychology Quarterly, 48, 97-107.

Yoneyama, T. (1976). Nihonjin no nakama ishiki [the Japanese concept of "peers"]. Tokyo, Japan: Kodansha.

Yoshikawa, M. (1978). Some Japanese and American cultural characteristics. In M. Prosser (Ed.), The cultural dialogue: An introduction to intercultural communication (pp. 220-251). Boston, MA: Houghton-Mifflin Co.

Yum, J. O. (1988). The impact of Confucianism on interpersonal relationships and communication patterns in East Asia. Communication Monographs, 55, 374-388. 
APPENDIX A

SCENARIOS 
Try to imagine you are talking with a stranger in the following conversation. After you read the conversation, answer the questions as if you were the listener in the conversation. There is a six-point scale for each question. Please circle the closest point to your answer.

Examples:

Q1. This flower is beautiful.

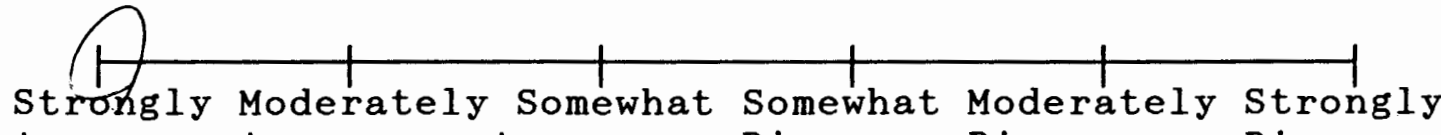
Agree Agree Agree Disagree Disagree Disagree

Q2. I do not like this flower.

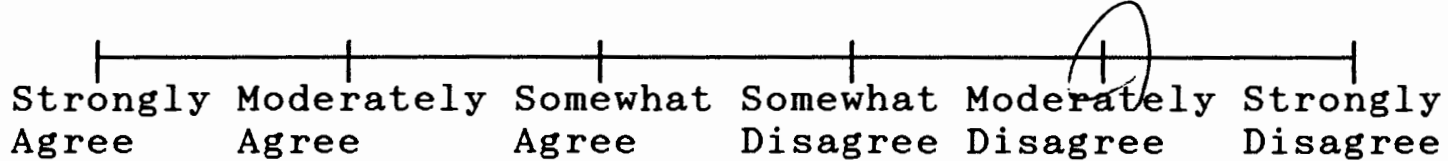

The conversation occurs in the following situation.

One day, you are waiting for a bus at a bus stop. A person you have never met before comes to the bus stop to wait for a bus. It seems the person left a watch. the person asks you what time it is, and you tell the time to the person. Then, the person starts talking to you while waiting for a bus.

Based on this situation, read the conversation between you and a stranger in the next page, and answer the following questions. 
CONVERSATION 1

( HIGH/INGROUP/MALE)

The man looks like the same age as you. He has the same textbook as yours. It seems that he is going to the same school as yours.

Man: Excuse me. Could you tell me what time it is?

You: It's $9: 22$.

Man: Thank you. Since I was in a hurry, I left my watch at home... So, the 9:25's bus hasn't come yet, has it?

You: No, not yet.

Man: Good.... Are you a student?

You: Yes.

Man: Then, are you going to school now?

You: Yes.

Man: Oh, me, too. I'm an English major at $\mathrm{X}$ University. How about you?

You: I'm an English major at X University, too.

Man: Oh really. Do you know a girl Y, then? She is my girlfriend. She is an English major, too.

You: Yes, I know her.

Man: I met her in a circle at school. I'm going out with her for five months. We often have conflict, though. We had a quarrel just the other day.... I'm pretty stubborn, so I can hardly say sorry to her. She apologized me last time, too. I feel sorry for her every time after a quarrel, but.... Anyway, we are getting along well so far, I think. In fact, I'm going out with her for dinner after school tonight.

You: That's nice.

Man: Well, the bus is coming. 
CONVERSATION 2

( LOW/INGROUP/MALE)

The man looks like the same age as you. He has the same textbook as yours. It seems that he is going to the same school as yours.

Man: Excuse me. Could you tell me what time it is?

YOu: It's $9: 22$.

Man: Thank you. Since I was in a hurry, I left my watch at home... So, the 9:25's bus hasn't come yet, has it?

You: No, not yet.

Man: Good.... Are you a student?

You: Yes.

Man: Then, are you going to school now?

You: Yes.

Man: I see... Is your school located near here?

You: Yes.

Man: Really....

(There is a silence between you and him for a while.)

Man: Excuse me, but what's your major?

You: My major is English.

Man: Oh, you are an English major. Me, too.

You: Oh really.

Man: Are you studying English Linguistics or something, then?

You: Yes....

Man: Well, the bus is coming. 
CONVERSATION 3

\section{( HIGH/OUTGROUP/MALE)}

The man looks like in his thirties. He wears a suit and has a brief case.

Man: Excuse me. Could you tell me what time it is?

You: It's $9: 22$.

Man: Thank you. Since I was in a hurry, I left my watch at home... So, the $9: 25^{\prime} \mathrm{s}$ bus hasn't come yet, has it?

You: No, not yet.

Man: Good.... Are you a student?

You: Yes.

Man: Then, are you going to school now?

You: Yes.

Man: I see. I'm going to work now. I'm working for $X$ Company.... What's your major at school?

You: My major is English.

Man: Oh, you are an English major. I majored in Economics at college, and my wife majored in French, I guess....

You: Really.

Man: My wife and I used to work for the same company, and I met her there. We married three years ago. We often have conflict, though. We had a quarrel just the other day.... I'm pretty stubborn, so I can hardly say sorry to her. She apologized me last time, too. I feel sorry for her every time after a quarrel, but.... Anyway, we are getting along well so far, I think. In fact, I'm going out with her for dinner after work tonight.

You: That's nice.

Man: Well, the bus is coming. 
CONVERSATION 4

\section{( LOW/OUTGROUP/MALE)}

The man looks like in his thirties. He wears a suit and has a brief case.

Man: Excuse me. Could you tell me what time it is?

You: It's $9: 22$.

Man: Thank you. Since I was in a hurry, I left my watch at home... So, the 9:25's bus hasn't come yet, has it?

You: No, not yet.

Man: Good.... Are you a student?

You: Yes.

Man: Then, are you going to school now?

You: Yes.

Man: I see.... Is your school located near here?

You: Yes.

Man: Really....

(There is a silence between you and him for a while.)

Man: Excuse me, but what's your major at school?

You: My major is English.

Man: Oh, you are an English major. You must study hard, then.

You: No, Not at all...

Man: I think it's convenient if you can speak English, isn't it?

You: Yes....

Man: Well, the bus is coming. 
CONVERSATION 5

( H IGH / INGROUP / FEMALE)

The woman looks like the same age as you. She has the same textbook as yours. It seems that she is going to the same school as yours.

Woman: Excuse me. Could you tell me what time it is?

You: It:s $9: 22$.

Woman: Thank you. Since I was in a hurry, I left my watch at home.... So, the 9:25's bus hasn't come yet, has it?

You: No, not yet.

Woman: Good.... Are you a student?

You: Yes .

Woman: Then, are you going to school now?

You: Yes.

Woman: Oh, me, too. I'm an English major at $X$ University. How about you?

You: I'm an English major at $X$ University, too.

Woman: Oh, really. Do you know a boy $Y$, then? He is my boyfriend. He is an English major, too.

You: Yes, I know him.

Woman: I met him in a circle at school. I'm going out with him for five months We often have conflict, though. We had a quarrel just the other day.... I'm pretty stubborn, so I can hardly say sorry to him. He apologized me last time, too. I feel sorry for him every time after a quarrel, but.... Anyway, we are getting along well so far, I think. In fact, I'm going out with his for dinner after school tonight.

You: That's nice.

Woman: Well, the bus is coming. 
CONVERSATION 6

( LOW/INGROUP/FEMALE)

The woman looks about the same age as you. She has the same textbook as yours. It seems that she is going to the same school as yours.

Woman: Excuse me. Could you tell me what time it is?

You: It's $9: 22$.

Woman: Thank you. Since I was in a hurry, I left my watch at home... So, the 9:25's bus hasn't come yet, has it?

You: No, not yet.

Woman: Good.... Are you a student?

You: Yes.

Woman: I see.... Is your school located near here?

You: Yes.

Woman: Really....

(There is a silence between you and her for a while.)

Woman: Excuse me, but what's your major?

You: My major is English.

Woman: Oh, you are an English major. Me, too.

You: Oh, really.

Woman: Are you studying English Linguistics or something, then?

You: Yes....

Woman: Well, the bus is coming. 
CONVERSATION 7

( HIGH /OUTGROUP/FEMALE)

The woman looks like in her thirties. She wears a suit and has a bag.

Woman: Excuse me. Could you tell me what time it is?

You: It's $9: 22$.

Woman: Thank you. Since I was in a hurry, I left my watch at home... So, the 9:25's bus hasn't come yet, has it?

You: No, not yet.

Woman: Good.... Are you a student?

You: Yes.

Woman: Then, are you going to school now?

You: Yes.

Woman: I see. I'm going to work now. I'm working for X Company.... What's your major at school?

You: My major is English.

Woman: Oh, you are an English major. I majored in Economics at college, and my husband majored in French, I guess....

You: Really.

Woman: My husband and I used to work for the same company, and I met him there. We married three years ago. We often have conflict, though. We had a quarrel just the other day.... I'm pretty stubborn, so I can hardly say sorry to him. He apologized me last time, too. I feel sorry for him every time after a quarrel, but.... Anyway, we are getting along well so far, I think. In fact, I'm going out with him for dinner after work tonight.

You: That's nice.

Woman: Well, the bus is coming. 
CONVERSATION 8

( LOW/OUTGROUP/FEMALE)

The woman looks like in her thirties. she wears a suit and has a bag.

Woman: Excuse me. Could you tell me what time it is?

You: It's $9: 22$.

Woman: Thank you. Since I was in a hurry, I left my watch at home.... So, the 9:25's bus hasn't come yet, has it?

You: No, not yet.

Women: Good.... Are you a student?

You: Yes.

Woman: Then, are you going to school now?

You: Yes.

Woman: Really....

(There is a silence between you and he for a while.)

Woman: Excuse me, but what's your major at school?

You: My major is English.

Woman: Oh, you are an English major. You must study hard, then.

You: No, not at all...

Woman: I think it's convenient if you can speak English, isn't it?

You: Yes....

Woman: Well, the bus is coming. 
APPENDIX B

QUESTIONS 
1. I think he/she could be a friend of mine.

2. I would like to have a friendly chat with him/her.

3. It would be difficult to meet and talk with hem/her.

4. We could never establish a personal friendship with each other.

5. He/she just wouldn't fit into my circle of friends.

6. He/she would be pleasant to be with.

7. I feel I know him/her personally.

8. He/she is personally offensive to me.

9. I don't care if I ever get to meet him/her.

10. I sometimes wish I were more like him/her.

11. He/she has something common with me in terms of social background.

13. He/she speaks too much.

14. What he/she says embarrasses me.

15. He/she is a different type of person from me.

16. He/she is thoughtful.

17. It would be difficult to enjoy talking with him/her.

18. I would like to know him/her better.

19. I don't think his/her choice of topics is appropriate. 20. I would like to talk with him/her in the bus. 


\section{APPENDIX C}

LETTER TO INSTRUCTORS IN JAPAN 
Department of Speech Communication

Portland State University

P.O.Box 751

Portland, Oregon 97201-0751

U.S.A.

March, 12,1991

Osamu Takahara

Kobe City University of Foreign Studies

9-1 Gakuenhigashi-machi, Nishi-ku

Kobe, Hyogo, Japan 673

Dear Mr. Takahara:

I am currently enrolled in the Department of Speech

Communication at Portland State University, and working on

the thesis about the concept of self-disclosure in initial

interaction between strangers in Japan. Because the purpose of the study is to explore the Japanese concept of selfdisclosure in comparison with the U.S. concept, I wish to conduct the research with Japanese who are currently living in Japan and have had limited interaction with North Americans. I am very interested in Japanese college students as the sample for my study. I wish to distribute the questionnaires to those individuals who participate in this study. However, it is physically and financially impossible for me in the Unite States to make contact with and give the questionnaire to complete to each respondent in Japan. So I would like to ask for your help.

First, I would like you to give me a complete list of the students in each of your class. Second, I would like you to distribute the questionnaires to all students in your classes. As soon as I send you the questionnaires by mail or facsimile, would you provide time in your class about 20 to 30 minutes for students to complete the questionnaires. Finally, I would like you to return the questionnaires by mail to me in the United States. I will pay the cost of this procedure.

I would appreciate it if you could help me with my research.

Sincerely,

Hizuru Sugita

Graduate Student
Dr. Susan B. Poulsen Assistant Professor Thesis Advisor 
APPENDIX D

LETTER TO SCHOOLS IN JAPAN 
Department of Speech Communication

Portland State University

P.O.Box 751

Portland, Oregon 97207-0751

U.S.A.

March, 12, 1991

Kobe City University of Foreign Studies

9-1 Gakuenhigashi-machi, Nishi-ku

Kobe, Hyogo, Japan 673

To whom it may concern:

My name is Hizuru Sugita. I graduated from Kobe City University of Foreign Studies in 1988. Currently, I am a graduate student in Department of Speech Communication at Portland State University, Portland, Oregon, the United states. I am working on the thesis which is entitled "the concept of self-disclosure in initial interaction between strangers in Japan."

The purpose of my study is to explore the Japanese concept of self-disclosure to compare it with the U.S. concept. I wish to conduct the research with Japanese college students who are currently living in Japan. I would like to understand the Japanese concept of self-disclosure, and would like to provide a sample of students with the questionnaires. However, it is physically and financially impossible for me in the United States to make contact with and give the questionnaire to each respondent in Japan. Therefore, if possible, I would like to distribute the questionnaires to students in a class through Professor Takahara in your school. I will directly talk to him about the research procedure.

I would appreciate it if you could let me know what procedure I need to complete to obtain permission for conducting this research at your school. I will be grateful for your assistance in this project.

Sincerely,

Hizuru Sugita

Graduate Student
Dr. Susan B. Poulsen Assistant Professor Thesis Advisor 


\section{APPENDIX E.}

\section{PERMISSION FROM SCHOOLS IN JAPAN}




\section{ch KOBE CITY UNIVERSITY OF FOREIGN STUDIES EQTE \\ Eב}

May 16,1991

Miss Hizuru Sugita

1705 SW 11th, \#822

Portland, OR 97201

U.S.A.

Dear Miss Sugita,

This is in reply to your request of conducting the questionnaring on undergraduate students at our university.

I have studied the purpose, significance, and the method of gathering data of your MA research project entitled "The concept of self-disclosure in initial interaction between strangers in Japan"

through the materials you sent to me.

In this connection, I am happy to inform you that I agree to furnish you with the opportunity to draw the sample from the undergraduate students in professor Takahara's classrooms in June 1991.

I hope this will be of assistance to your research.

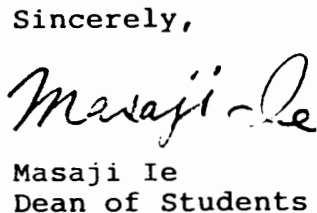

MI : ot

9-1, GAKUEN-HICASHI-MACHI, NISHI-KU, KOBE 673, IAPAN 
May 16, 1991

Hizuru sugita

Department of speech Communication

Portland State University

P.O.Box 751

Portland, OR 97207-0751

Dear Miss Sugita:

Saint Agnes' Junior College hereby agree to give the questionnaires to the students in Miss Tanioka's classes in the research project entitled " the concept of self-disclosure in initial interaction between strangers in Japan" conducted by Hizuru sugita under the supervision of Dr. Susan Poulsen.

I understand that the study involves answering the biographical sheets and the questionnaires in the classrooms. It has been explained to me that the purpose of the study is to examine how the degree of self-disclosure influences social attraction in initial interaction betweem strangers in Japanese culture and that it is necessary for the researcher to have native Japanese speaking college students as her respondents.

Hizuru sugita has offered to answer any questions about the study. I understand that I am free to withdraw from participation in this study at any time without jeopardizing my relationship with Portland State Universtiy.

It would be my pleasure if I could help you with your research.

Sincerely,

Hiroyoshi Harakawa

Dean of the Instruction Department Hiroyoshi Htarakawa 


\section{Informed Consent}

We, icichunimenity, hereby agree to participate in the research project entitled "the concept of self-disclosure in initial interaction between strangers in Japan" conducted by Hizuru Sugita under the supervision of Dr. Susan Poulsen.

We understand that the study involves answering the biographical sheet and the questionnaires in the classroom.

It has been explained to us that the purpose of the study is to learn how the degree of self-disclosure influences social attraction in initial interaction between strangers in Japanese culture.

We way not receive any direct benefit from participation in the study, but our participation may help to increase knowledge which may benefit others in the future.

Hizuru Sugita has offered to answer any questions we way have about the study and what is expected of us in the study. We have been assured that all information we give will be kept confidential and that the identity of all subjects will remain anonywous in the study.

We understand that we are free to withdraw from participation in this study at any time without jeopardizing our relationship with Hizuru Sugita, the researcher of the study, Portland State University. We have read and understand the foregoing information.

signature Rev zuhe H. Inome

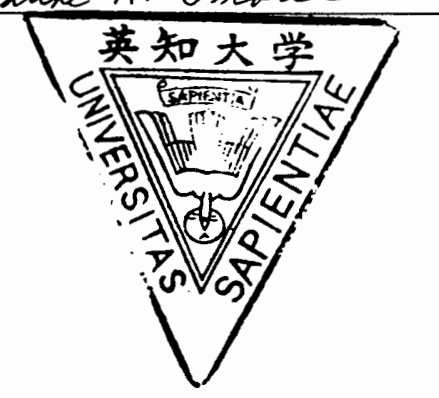
Date My 15, 1991 
APPENDIX F

COVER LETTER 
My name is Hizuru Sugita. I am a graduate student in the Department of Speech Communication at Portland State University, Oregon, the United States. I am working on the Master thesis now, and would like to ask for your assistance in my research. The purpose of the study is to investigate conversation in initial interaction between strangers in Japan. Therefore, I need Japanese respondents currently living in Japan for the study.

This research form consists of the informed consent, the biographical sheet, and the research questionnaire. Because of the concern of the Human Subjects Research Review Committee for participants in research studies, I ask you to read the informed consent and sign your name before answering the questionnaire. There is no obligation for you to participate in this research. I assure you that if you participate, your name will not be used in the study.

Before the research questionnaire, I ask you to answer some biographical questions. In the research questionnaire, you will be asked to read a particular situation and a conversation which occurs in the situation. Pleas try to imagine you and a stranger are interacting and read the conversation, and answer the following questions as if you were the listener.

Pleas read the informed consent carefully and sign your name both in Japanese and English if you are willing to participate in the research. After you sign your name, 
115

please answer the questionnaire. I will be grateful for your assistance in the research.

Hizuru Sugita 
APPENDIX G

INFORMED CONSENT 
I, hereby agree to serve as a subject in the research project entitled "the concept of self-disclosure in initial interaction between strangers in Japan" conducted by Hizuru Sugita under the supervision of Dr. Susan B. Poulsen.

I understand that the study involves answering the biographical sheet and the research questionnaire in the classroom.

It has been explained to me that the purpose of the study is to learn the initial interaction between strangers in Japanese culture.

I may not receive any direct benefit from participation in the study, but my participation may help to increase knowledge which may benefit others in the future.

Hizuru Sugita has offered to answer any questions I may have about the study and what is expected of me in the study. I have been assured that all information I give will be kept confidential and that the identity of all subjects will remain anonymous in the study.

I understand that I am free to withdraw from participation in this study at any time without jeopardizing my relationship with Hizuru Sugita, the researcher of the study, Portland State University, or the school I am currently enrolled at.

I have read and understand the foregoing information.

Signature

Date

If you experience problems that are the result of your participation in this study, please contact the Chair of the Human Subjects Research Review Committee, Office of Grants and Contracts, 345 Cramer Hall, Portland State Universality, (503) 725-3417. 
APPENDIX H

BIOGRAPHICAL SHEET 
1. Age years old

2. Gender (please circle the number) 1. male 2. female

3. Have you ever been to the United states, Canada, Australia, New Zealand, Britain, or European countries?

1 . yes 2 . no

If "yes,"

At what age did you go to those countries?

Totally how long did you stay in those countries? weeks months years

4. How long and where have you studies English as the second foreign language?

How long? years

Where? 1. at junior high or high school

2. at college

3. at English school

4. at other places

5. Do you have any interaction with North Americans or people from Western countries on daily basis?

1 . yes 2. no

If "yes,"

With how many people do you interact per week? people per week

How often do you interact with them per week? hours per week

In what situation do you interact with them?

1. with instructors in class

2. with family members at home

3. with friends

4. in other situations

In what language do you interact with them?

1. in Japanese

2. in English

3. in other languages 